\title{
Assessment of coal gasification in a pressurized fixed bed gasifier using an ASPEN plus and Euler-Euler model
}

\author{
Tamer M. Ismail ${ }^{1}$ Mingliang $\mathrm{Shi}^{2,3} \cdot$ Jianliang $\mathrm{Xu}^{2,3} \cdot$ Xueli Chen $^{2,3} \cdot$ \\ Fuchen Wang ${ }^{2,3} \cdot$ M. Abd El-Salam ${ }^{4}$
}

Received: 23 April 2020/Revised: 27 June 2020/Accepted: 30 August 2020/Published online: 29 September 2020

(C) The Author(s) 2020

\begin{abstract}
With the help of Aspen Plus, a two-dimensional unsteady CFD model is developed to simulate the coal gasification process in a fixed bed gasifier. A developed and validated two dimensional CFD model for coal gasification has been used to predict and assess the viability of the syngas generation from coal gasification employing the updraft fixed bed gasifier. The process rate model and the sub-model of gas generation are determined. The particle size variation and char burning during gasification are also taken into account. In order to verify the model and increase the understanding of gasification characteristics, a set of experiments and numerical comparisons have been carried out. The simulated results in the bed are used to predict the composition of syngas and the conversion of carbon. The model proposed in this paper is a promising tool for simulating the coal gasification process in a fixed bed gasifier.
\end{abstract}

Keywords Fixed bed gasifier $\cdot$ Aspen plus $\cdot$ Euler-Euler model $\cdot$ Coal

\section{List of symbols}

A Pre-exponent factor, particle surface area $\left(\frac{\mathrm{kg}}{\mathrm{m}^{2} \mathrm{sPa}}, \mathrm{m}^{2}\right)$

$C_{\mathrm{p}} \quad$ Specific heat capacity $(\mathrm{J} / \mathrm{kg} \mathrm{K})$

$C_{\mathrm{sw}} \quad$ Swilling coefficient

$D \quad$ Diffusion rate $\left(\mathrm{m}^{2} / \mathrm{s}\right)$

$d_{\mathrm{p}} \quad$ Particle diameter $(\mathrm{m})$

E Activation energy $(\mathrm{J} / \mathrm{mol})$

Tamer M. Ismail and Mingliang Shi have contributed equally to this work.

Tamer M. Ismail

tamer.ismail@eng.suez.edu.eg

1 Mechanical Engineering Department, Suez Canal University, Ismailia, Egypt

2 Key Laboratory of Coal Gasification and Energy Chemical Engineering of Ministry of Education, East China University of Science and Technology, Shanghai, China

3 Shanghai Engineering Research Center of Coal Gasification, East China University of Science and Technology, Shanghai, China

4 Department of Basic Science, Cairo University, Giza, Egypt $h_{\mathrm{f}} \quad$ Enthalpy of formation $(\mathrm{J} / \mathrm{kg})$

$h_{\mathrm{rs}} \quad$ Radiation heat transfer coefficient $(\mathrm{m} / \mathrm{s})$

$h_{\mathrm{rv}} \quad$ Effective radiation heat transfer coefficient of the voids $(\mathrm{m} / \mathrm{s})$

$K \quad$ Extinction coefficient

$k \quad$ Turbulent kinetic energy $\left(\mathrm{m}^{2} / \mathrm{s}^{2}\right)$

$k_{\mathrm{c}} \quad$ Char combustion reaction rate $(\mathrm{kg} / \mathrm{s})$

$k_{\mathrm{cr}} \quad$ Kinetic rate $(1 / \mathrm{s})$

$K_{\text {cd }} \quad$ Diffusion rates $\left(\mathrm{kg} / \mathrm{atmm}^{2} \mathrm{~s}\right)$

$k_{\mathrm{f}} \quad$ Thermal conductivity of the fluid (W/m K)

$k_{\mathrm{s}} \quad$ Thermal conductivity of the pure $(\mathrm{W} / \mathrm{m} \mathrm{K})$

$k_{\text {eff }} \quad$ Effective thermal conductivity (W/m K)

$k_{\text {eff,0 }} \quad$ The thermal conductivity for no fluid flow (W/m K)

$l_{\mathrm{s}} \quad$ Equivalent thickness a layer of solid (m)

$P_{\mathrm{O} 2} \quad$ Partial pressure of oxygen $(\mathrm{Pa})$

$q_{\mathrm{r}} \quad$ Radiative flux density (W)

$R \quad$ Gas universal constant (mol K)

$R_{\text {evp }} \quad$ Moisture evaporation rate $(\mathrm{kg} / \mathrm{s})$

$R_{\mathrm{c}} \quad$ Char consumption rate $(\mathrm{kg} / \mathrm{s})$

$R e \quad$ Reynolds number

$R_{\mathrm{v}} \quad$ Volatile matter in solid rate $(\mathrm{kg} / \mathrm{s})$

$S h \quad$ Sherwood number

$S_{\Phi} \quad$ Source term

$T_{\infty} \quad$ Environment temperature (K) 
$T_{\mathrm{g}} \quad$ Gas temperature $(\mathrm{K})$

$T_{\mathrm{s}} \quad$ Solid temperature $(\mathrm{K})$

$t \quad$ Time (min)

$X \quad$ Degree of burnout $\left(\frac{\mathrm{kmol}}{\mathrm{kmol}}\right)$

$Y_{\mathrm{i}} \quad$ Mass fraction of species

$u \quad$ Velocity component in $\mathrm{x}$-direction $(\mathrm{m} / \mathrm{s})$

\section{Greek letters}

$\alpha \quad$ Burning mode

$\beta \quad$ Gas-solid friction coefficient

$\mu \quad$ Dynamic viscosity $(\mathrm{kg} / \mathrm{m} \mathrm{s})$

$\phi \quad$ Void fraction in bed

$\varepsilon \quad$ Dissipation rate of turbulent kinetic energy $\left(\mathrm{m}^{-2} \mathrm{~s}^{-3}\right)$

$\epsilon \quad$ Emissivity

$\emptyset \quad$ Mechanism factor

$\rho \quad$ Density $\left(\mathrm{kg} / \mathrm{m}^{3}\right)$

$\lambda_{\mathrm{g}} \quad$ Thermal dispersion coefficient

$\lambda_{\text {mix }} \quad$ Effective dispersion coefficient

$\Phi \quad$ Dependent variable

\section{Introduction}

With the economic development in our country, the steel industry is facing the transformation and upgrading, the demand for coal is declining, and a severe overcapacity appears. Therefore, under the critical situation that the traditional coal industry is facing elimination and rectification, the development of new coal gasification technology has become an essential direction for the current restructuring and upgrading of the coal industry (Cau et al. 2012). Some enterprises have changed their original capacity for producing metallurgical coal to produce gasified coal. Because of their large particle size, $(15-35 \mathrm{~mm})$ cannot be directly applied to the fluidized bed and the entrained flow bed, so they are needed to pretreat first, which will increase the cost. Therefore, a coal-bed classification oxygen fixed bed gasifier is proposed (Xu et al. 2016).

Adopting the form of graded oxygen can reduce the temperature of the flame at the exit of the nozzle, supplement oxygen in the appropriate part of the combustion bed of the fixed bed, and increase the temperature to promote the gasification reaction. On the one hand, the graded oxygen supply can decouple the oxygen supply of the main nozzle of the gasifier from the oxygen equivalent required by the reaction and reduce its oxygen load.

On the other hand, the graded oxygen improves the working environment at the nozzle and prolongs the service life of the nozzle. Graded oxygen can also make the combustion layer temperature distribution more uniform, so that the fixed bed temperature distribution within the more reasonable while increasing the average temperature of the combustion layer, the gasification effect is optimized (ECUST 2005).

In a fixed-bed gasifier, as the bed height changes, there are different distributions for temperature, chemical reaction rate, and porosity and gas composition. Among these various distributions of these parameters will have a significant impact on gasifier efficiency and operational stability. However, due to the complicated flow in the bed and the reaction process, it is tough to obtain valid data through experiments (Xu et al. 2016). The development of Computational Fluid Dynamics (CFD) provides a new method for studying the internal flow reaction in a fixed bed. At the same time, a large number of experiments are needed to obtain the parameters of oxygen to coal ratio and steam to coal ratio. This paper uses a large process simulation software Aspen Plus. The simulation results obtained through thermodynamic equilibrium can guide the experiment and significantly reduce the experimental cycle.

Many researchers studied and investigated the gasification process, as well as, the coal gasification. Ai et al. (2011) used CFD software to simulate the flow field inside a fixed bed gasifier Based on the establishment of the actual gasifier geometry model, the $k-\varepsilon$ two-equation model, the fluid transport model, the P1 model and the SIMPLE method are used to solve the N-S equation. The concentration distribution and temperature distribution in the furnace were simulated. Wu et al. (2013) developed a 2D CFD model to simulate the gasification process in the lower suction gasifier. The model includes drying, pyrolysis, combustion, and gasification. In this paper, a multiphase Euler-Euler model is used, considering the change of momentum, mass, and energy. The simulation results are compared with the experimental data, and there is a good consistency.

Masmoudi et al. (2014) established the two dimensional model of the reduction zone in the biomass suction fixed bed gasifier. The model is mainly based on the mass, momentum and energy conservation of solid and mobile phase and coupled with chemical reaction kinetics. The kinetic parameters in the model are derived from the previous literature, and the effective factors are used to quantify the mass transfer resistance in the bed.

The calculated results are compared with the experimental values, and good consistency is obtained. Ismail and El-Salam (2015) studied the gasification and combustion processes in the updraft gasifier, and the reaction rate of the process is considered at the same time. In the model, the particle flow dynamics (KTGF) is introduced to simulate the solid phase, and the gas phase turbulence is simulated through the k-epsilon model. The gasification process, the 
temperature of gas phase and solid phase and the concentration curve of the component are studied by the model. On one hand, the model can predict the distribution of temperature and gas composition well. On the other hand, the simulation results are compared with other models and experimental data, and the comparison results show that the existing models can provide more accurate results.

Chen et al. (2012) simulated the fixed bed coal gasification process by Aspen Plus software. A series full mixing reactor with FORTRAN gasification kinetics subroutine was used instead of Gibbs reactor. The results show that the model is in good agreement with the results of the actual fixed bed gasification. Duan et al. (2015) simulated the coal integrated gasification using Aspen Plus software platform.

The effects of different reaction temperature, the mass ratio of glycerol to biomass, and the ratio of gasifying agent to material and reaction pressure on hydrogen production by $\mathrm{CO}$ gasification of pure glycerol and biomass, crude glycerin and biomass were investigated. Kong et al. (2014) studying an equivalent compartment model (CM) using the Aspen Plus of coal gasification in an entrained flow gasifier. The effects of gas production on gasification gas composition, calorific value, conversion rate and carbon conversion rate were studied. The composition of gasification gas, the low calorific value of gasification gas, heat conversion efficiency, and carbon conversion rate are predicted under different operating conditions.

Shabbar and Janajreh (2013) use the Gibbs free energy minimization method to establish the model of the airflow bed coal gasifier. The influence of the main operating parameters of the gasifier on the gasification results was studied. The simulation results are analyzed. It is found that the model is correct and can be applied to the calculation of chemical and thermodynamic equilibrium of some gasification processes with complex reaction mechanism. Liu et al. (2013) adopted the Aspen Plus industrial process simulation software, followed the Gibbs free energy minimization method and the reaction equilibrium model to build BGL gasifier model. The gasification simulation of 3 different kinds of coal is carried out.

The results show that the model is highly consistent with the actual operating results of BGL gasifier, and can be applied to the calculation of chemical and thermodynamic equilibrium of some gasification processes with complex reaction mechanism, and the influence of different operation parameters on the gasification performance of BGL gasifier is also studied.

The CFD model used in this paper is a homemade model (Ismail and El-Salam 2015, 2017; Ismail et al. 2016, 2017; Monteiro et al. 2017). The model is based on the mass and energy conservation equations, including energy exchange between gas and solid two-state and radiative heat transfer from solid particles. Including different gasifier processes: coal drying, pyrolysis, oxidation of carbon and volatile materials, chemical reduction of $\mathrm{H}_{2}, \mathrm{CO}, \mathrm{CO}_{2}$ and $\mathrm{CH}_{4}$, and reforming of hydrocarbons. The kinetics associated with gas-solid gasification have been studied extensively during the last decades. Nevertheless, the understanding of these kinetics and their many factors of influence are not completely mastered.

The proposed model can be used in the future to simulate and analyze the effects of nozzle structure, position, dip angle, gasification flux and composition on the reaction zone temperature, component concentration, coal carbon conversion and so on, Oxygen fixed bed pressurized gasifier to provide optimal design support. Aspen plus set up a set of gasification coal grading oxygen fixed bed gasifier mathematical model for the future study of oxygen and steam and preheating temperature of gasification syngas gas production and effective gas composition impact equipment operating process parameters to provide a reference.

\section{Experimental test rig}

The commercial-scale gasifier geometry is shown in Fig. 1. The inner diameter of the combustion chamber is about $3600 \mathrm{~mm}$. There are six nozzles fixed around the bottom of the gasifier, and the total oxygen flow rate is about $15,000 \mathrm{~N} \mathrm{~m}^{3} / \mathrm{h}(\operatorname{vol} \%>99.6)$. The steam is mixed with the oxygen. The nozzle jet velocity is about $150 \mathrm{~m} / \mathrm{s}$. The operation condition of the gasifier is shown in Table 1 . The coal-bed height (straight section) of the standard operation is about $9 \mathrm{~m}$. The refractory bricks are lined inside the gasifier and the wall boundary using is approximately $8.82 \mathrm{~W} / \mathrm{m}^{2} \mathrm{~K}$ heat transfer coefficient and $330 \mathrm{~K}$ free stream temperature.

The coal size and composition data are listed in Table 2. In order to discharge the molten slag from the bottom of the gasifier, about $15 \%$ mass content $\mathrm{CaCO}_{3}$ is added. And the temperature of molten slag is about $1300{ }^{\circ} \mathrm{C}$. Tables 3 and 4 displace the product and by-product data of a commercial operation gasifier.

\section{Mathematical formulation}

\subsection{Euler-Euler model}

Thermochemical transformation of carbon compounds is a complex chemical process. During this transformation, homogeneous and heterogeneous reactions take place simultaneously. Homogeneous reactions in the gas phase are described by relatively simple equations and can approach equilibrium at the usual temperatures and pressures encountered in modern gasifiers. On the other hand, the 


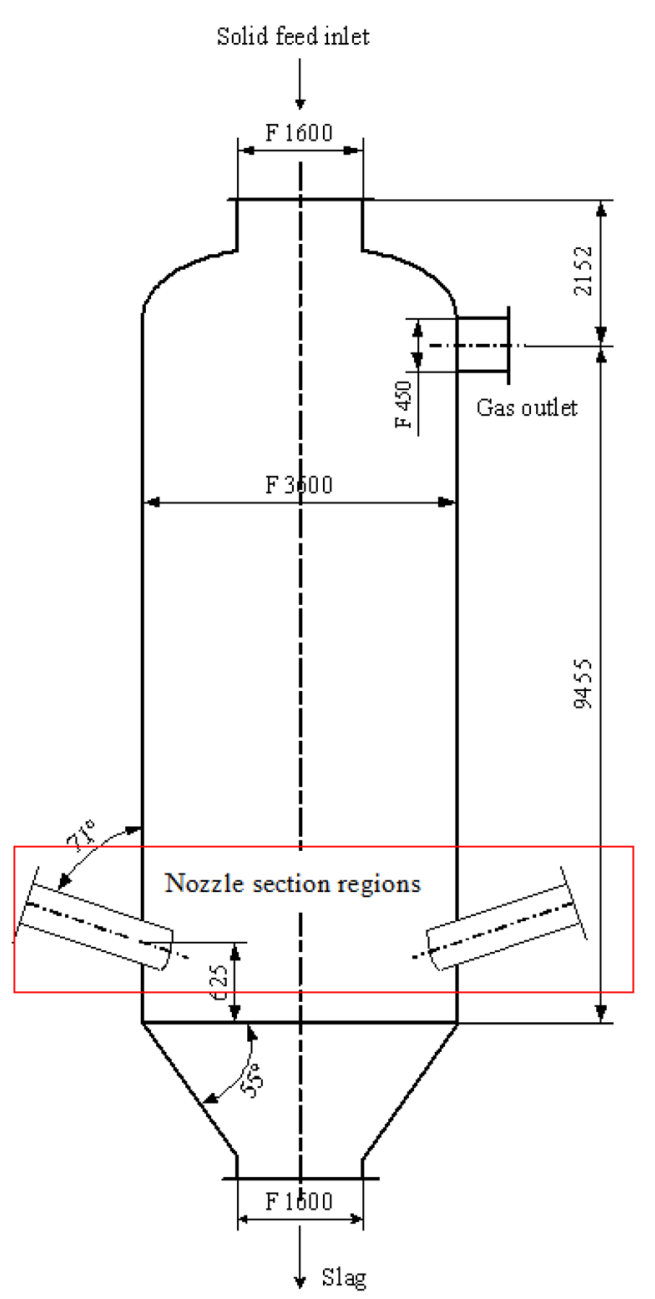

Fig. 1 Gasifier geometry

heterogeneous solid gas reactions are much more complex, in particular because of the heat and mass transfers that take place. The source terms that are constituted is needed by the products of the chemical reactions concerning the equations of conservation of mass, and flows of energy exchanged concerning the energy conservation equation.

The coal undergoes the devolatilization (or pyrolysis) step producing a set of gaseous products (volatiles) on the one hand and a solid residue (the char) consisting essentially of carbon. Each of these two products follows a specific transformation path leading to the production of gaseous fuel called synthesis gas $\left(\mathrm{H}_{2}+\mathrm{CO}\right)$, Fig. 2 shows a simplified diagram of the gasification process.

The gaseous phase consists of so-called primary volatiles composed of light $\left(\mathrm{CO}, \mathrm{H}_{2}, \mathrm{CO}_{2}\right.$, and $\left.\mathrm{CH}_{4}\right)$ and heavy (tar) or light $\left(\mathrm{H}_{2} \mathrm{O}\right)$ condensates. At sufficiently high-temperature levels, the light hydrocarbons and the tars split to give slightly lighter molecules called secondary or tertiary volatiles: this is referred to as homogeneous or secondary thermal cracking.
Table 1 Gasifier operation condition

\begin{tabular}{lcl}
\hline Item & $\begin{array}{l}\text { Normal } \\
\text { operation } \\
\text { parameter }\end{array}$ & Remarks \\
\hline Coal flow rate $(\mathrm{t} / \mathrm{d})$ & 976 & \\
Fluxing agent $\left(\mathrm{CaCO}_{3}\right)(\mathrm{t} / \mathrm{d})$ & 144 & \\
Oxygen flow rate $\left(\mathrm{N} \mathrm{m}^{3} / \mathrm{h}\right)$ & 15,000 & Normal temperature \\
Steam flow rate $(\mathrm{kg} / \mathrm{h})$ & 14,000 & $P>3.7 \mathrm{MPa}(\mathrm{G})$ \\
& & $T=425^{\circ} \mathrm{C}$ \\
\hline
\end{tabular}

Table 2 Coal particle size distribution

\begin{tabular}{lc}
\hline Particle size $(\mathrm{mm})$ & Distribution $(\%)$ \\
\hline $0-10$ & 5 \\
$10-25$ & 70 \\
$25-50$ & 20 \\
$50-100$ & 5 \\
\hline
\end{tabular}

Table 3 Commercial gasifier operation results

\begin{tabular}{ll}
\hline Parameter & Value \\
\hline Gasifier operation pressure $(\mathrm{MPa}(\mathrm{G}))$ & 3.0 \\
Gas flow rate $($ dry basis $)\left(\mathrm{N} \mathrm{m}^{3} / \mathrm{h}\right)$ & 70,900 \\
$\left(\mathrm{CO}+\mathrm{H}_{2}\right)$ flow rate $\left(\mathrm{N} \mathrm{m}^{3} / \mathrm{h}\right)$ & 63,000 \\
$\mathrm{CH}_{4}$ flow rate $\left(\mathrm{N} \mathrm{m}^{3} / \mathrm{h}\right)$ & 2900 \\
Syngas temperature $\left({ }^{\circ} \mathrm{C}\right)$ & 442 \\
Gas composition $(\mathrm{mol} \%)$ & - \\
$\mathrm{H}_{2}$ & 25.93 \\
$\mathrm{CO}$ & 62.77 \\
$\mathrm{CH}_{4}$ & 4.05 \\
$\mathrm{CO}_{2}$ & 5.94 \\
$\mathrm{H}_{2} \mathrm{~S}, \mathrm{COS}$ and $\mathrm{CS}_{2}$ & 0.69 \\
$\mathrm{NH}_{3}, \mathrm{HCl}$ and $\mathrm{HCN}$ & 0.03 \\
$\mathrm{~N}_{2}$ and $\mathrm{Ar}$ & 0.36 \\
$\mathrm{C}_{n} \mathrm{H}_{m}$ & 0.23 \\
\hline
\end{tabular}

The solid residue (char) is oxidized by water vapor, carbon dioxide, and oxygen to produce the synthesis gas. These transformations, which are encompassed by the gasification of the char, involve heterogeneous chemical reactions and heat and mass transfer mechanisms, the study of which constitutes the core of this work.

In this work, a mathematical model of coal gasification in a fixed bed gasifier is proposed. The model is based on 
Table 4 Byproduct in the syngas

\begin{tabular}{lcl}
\hline Parameter & Value & Remarks \\
\hline Tar $(\mathrm{kg} / \mathrm{h})$ & 0 & \\
Light oil $(\mathrm{kg} / \mathrm{h})$ & 140 & Molecular formula unknown \\
BTX $(\mathrm{kg} / \mathrm{h})$ & 240 & \\
Phenols $(\mathrm{kg} / \mathrm{h})$ & 60 & \\
\hline
\end{tabular}

the conservation equation of mass and energy. Including energy exchange between solid and gas phases and radiative heat transfer from solid particles. Different gasification processes are introduced: coal drying, pyrolysis, oxidation of char and volatile matter, chemical reduction of $\mathrm{H}_{2}, \mathrm{CO}$, $\mathrm{CO}_{2}$ and $\mathrm{CH}_{4}$ by char, and hydrocarbon reforming.

Turbulent flow is captured by using $k-\varepsilon$ model. The Finite rate/Eddy dissipation model is used to solve the gasphase mass transport equation. Moreover, the turbulent diffusion effect is taken into account. Particle size varies with particle density.

The model will be validated experimentally in a fixed bed gasifier. So, the model can be used as a tool to study the influence of different process parameters in future. Such as coal particle diameter effect, airflow velocity, equivalence ratio, oxygen ratio, the inlet temperature of the gasifying agent and steam to coal ratio on the gasification process, the efficiencies, the temperature/gas composition distribution in the bed, reaction distribution and the multiphase flow information around the nozzles exit region.
Understanding the gasification/combustion characteristics of coal in a small-scale will help with the clean and efficient use in a large-industrial scale with the real effect of the process. Table 5 shows physical and chemical properties of present coal used in the proposed model.

Firstly, a kinetic model must be defined for all the chemical reactions involved, as the products of these reactions are known to constitute the source term of the mass conservation equation for each species solution. Similarly, the heat of reaction is involved in the calculation of the source term of the energy conservation equation.

The morphological structure of the material is a parameter that significantly influences heterogeneous reactions. The properties representing this parameter are numerous: porosity, tortuosity, specific surface area, porous distribution, and pore size (Mermoud 2006; Klose and Wölki 2005; Cetin et al. 2004; Lussier et al. 1998; Mehrabian et al. 2014). Considering all these issues, the modeling of the morphological structure of the char remains very complicated.

In the present model, the adaptation of Mermoud (2006) was used, which state that the increase of the reactive surface is accompanied by the reduction of the density of the char so that the two phenomena remain compensatory. Thus, the term $\left(S_{r} \times \rho_{\eta}\right)$ is conserved and remains constant during the conversion (Lussier et al. 1998). It is expressed regarding the evolution of the reactive surface as a function of the conversion rate by the following relation (Manocha et al. 2002; Golfier et al. 2004):

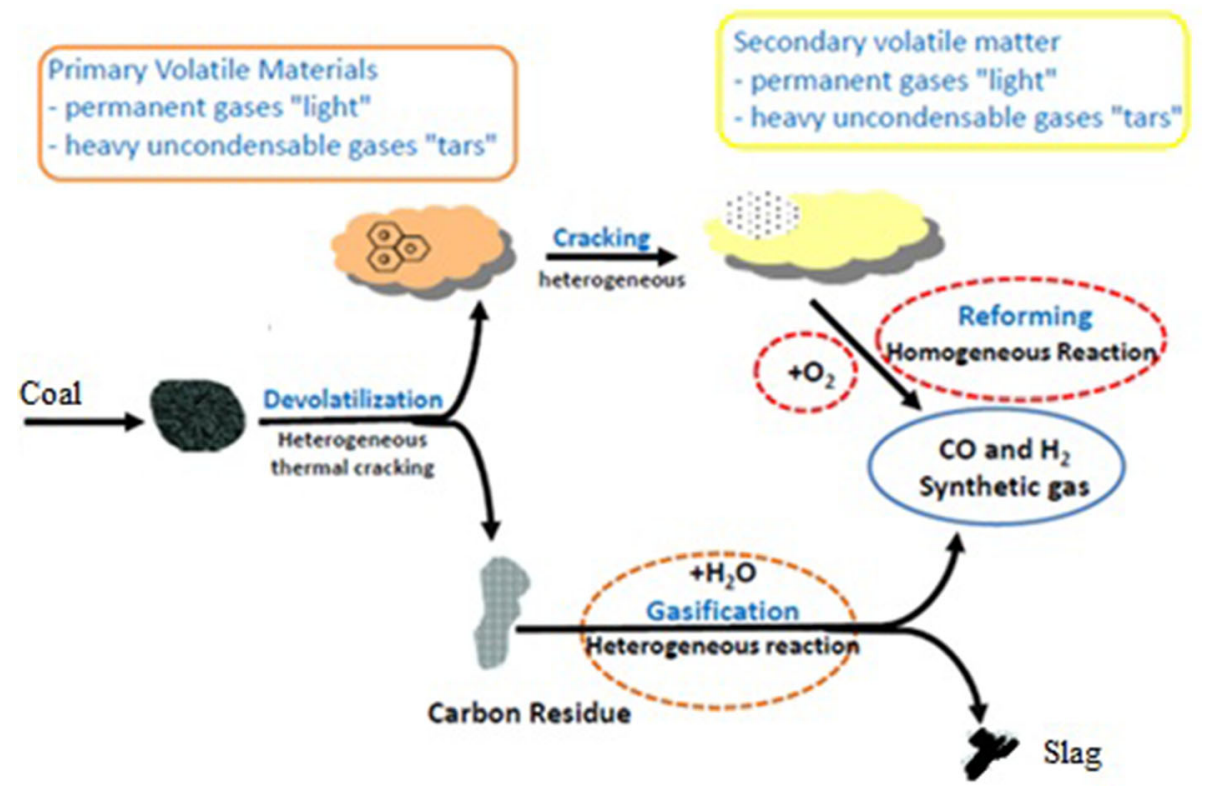

Fig. 2 Simplified overview of the various mechanisms involved in the gasification process 
Table 5 Coal properties

\begin{tabular}{lll}
\hline Category & Item & Value \\
\hline Ultimate analysis & $\mathrm{N}$ & 0.95 \\
$(\%)$ & $\mathrm{C}$ & 88.67 \\
& $\mathrm{H}$ & 2.82 \\
& $\mathrm{O}$ & 5.20 \\
& $\mathrm{C}$ & 10.01 \\
& $\mathrm{~S}$ & 2.35 \\
& $\mathrm{HHV}(\mathrm{MJ} / \mathrm{kg}$ & 33.28 \\
& coal) & \\
Proximate analysis & Ash & 19.73 \\
& Volatile matter & 3.97 \\
& Fixed carbon & 70.70 \\
& Moisture & 5.60 \\
& Empirical & $\mathrm{CH}_{0.098} \mathrm{O}_{0.011} \mathrm{~N}_{0.00236} \mathrm{~S}_{0.00256}$ \\
& formula & \\
\hline
\end{tabular}

$S_{r}(t)=S_{r}(0) \frac{\rho_{b}, o}{\rho_{(t)}}=S_{r}(0) \frac{1-\phi_{o}}{1-\phi_{t}}=S_{r}(0) \frac{1}{1-X(t)}$

In this case, the structure function is written as follows:

$f(X)=\frac{1}{1-X}$

This function takes into account the variations related to the morphological structure of the particle that occur during the conversion of the parameters, which was consistent with the experimental results of Refs. Klose and Wölki (2005), Mehrabian et al. (2014).

\subsection{Kinetic model}

The volatile matter emitted always depends on both the devolatilization conditions (for example, the heating rates, and the final temperature) and the fuel type. Also, the released volatile matter contains gaseous hydrocarbons. Coal pyrolysis and composition balance of coal are taken into account as follows:

$$
\begin{aligned}
& \text { Coal } \rightarrow \text { Carbon }+ \text { Volatile }+\mathrm{H}_{2} \mathrm{O}+\text { Ash } \\
& \text { Volatile }\left(\mathrm{CH}_{0.098} \mathrm{O}_{0.011} \mathrm{~N}_{0.00236} \mathrm{~S}_{0.00256}\right) \\
& =\underbrace{n_{1} \mathrm{CO}_{2}+n_{2} \mathrm{CO}+n_{3} \mathrm{H}_{2}+n_{4} \mathrm{CH}_{4}+n_{5} \mathrm{~N}_{2}}_{\text {volatilecracking }}
\end{aligned}
$$

This work assumes that the volatile matter contains Carbon, Hydrogen, Oxygen, and Nitrogen, while the Sulphur is ignored. The current model can determine the elements' contents and the volatile heating value automatically depending on the ultimate and the proximate data. As a result, the model can be efficiently utilized for the study of different types of coal (Di Blasi 2004).
Coal $\stackrel{k_{1}}{\longrightarrow}\left(1-Y_{1}\right)$ char $+Y_{1} V_{1} \quad$ (low temperature)

Coal $\stackrel{k_{2}}{\longrightarrow}\left(1-Y_{2}\right)$ char $+Y_{2} V_{2} \quad$ (high temperature $)$

$k_{i}=A_{i} \exp \left(-\frac{E_{i}}{R T}\right)$

Here $V$ is the volatile and $Y$ is volatilization coefficient $\left(Y_{1}=0.3\right.$ and $\left.Y_{2}=1.0\right)$. Besides, $k_{i}$ is the Arrhenius kinetics rate constants that affect and control the devolatilization model for different temperature ranges.

$A_{1}=2 \times 10^{5} \frac{\mathrm{kg}}{\mathrm{m}^{2} \mathrm{sPa}^{0.5}}$

$A_{1}=1.3 \times 10^{7} \frac{\mathrm{kg}}{\mathrm{m}^{2} \mathrm{sPa}^{0.5}}$

$E_{1}=1.046 \times 10^{8} \mathrm{~J} / \mathrm{kmol}$

$E_{2}=1.67 \times 10^{8} \mathrm{~J} / \mathrm{kmol}$

While the volatile matter always includes a wide range of species, it can be represented as a single virtual material (Prando et al. 2016). The reason for this is that the release kinetics of the individual gaseous species over the devolatilization process has not been clarified yet, due to the complexities of the chemical reactions concerning the different intermediates and final gaseous products. Additionally, regarding combustion, the complicated formation mechanism for the volatile matter is not normally required. It is because the gases are burned instantly under the appropriate temperature and oxygen. This instantaneous burning minimizes the necessary of computational calculations.

In the present work, coal with around 5\% moisture content is fed into the fixed bed gasifier with the inlet air from the bottom. The ignition of the coal starts from the bottom of the gasifier using six nozzles. A detailed kinetic model for the different reactions process is summarized in Table 2 with all reactions and kinetic rate parameters (Prando et al. 2016).

\subsubsection{Particle shrinkage model}

By studying the average diameter of the coal particles and analyzing the fuel and char morphology, it is found that particle shrinkage during the devolatilization process is significantly affected by the following swelling coefficient equation:

$\frac{d_{\mathrm{p}}(t)}{d_{\mathrm{p}, 0}}=1+\left(C_{\mathrm{sw}}-1\right) \frac{\left(1-M C_{0}\right) m_{\mathrm{p}, 0}-m_{\mathrm{p}}}{V M_{0}\left(1-M C_{0}\right) m_{\mathrm{p}, 0}}$

Here $M C_{0}$ is the initial moisture content of the coal and $V M_{0}$ is the initial volatile material content of the studied coal obtained from proximate analysis. The term 
$\frac{\left(1-M C_{0}\right) m_{\mathrm{p}, 0}-m_{\mathrm{p}}}{V M_{0}\left(1-M C_{0}\right) m_{\mathrm{p}, 0}}$ is the ratio between the total volatile mass and the mass that has been devolatilized of the particle.

During the devolatilization process, it is found that the particles' size depends on the value of the swelling coefficient. The size increases if the swelling coefficient is larger than one, and decreases when the swelling coefficient becomes less than one. For example, the diameter reaches the double if the value of the swelling coefficient becomes 2.0. Besides, the swelling coefficient is obtained by the morphological analysis, and can be calculated by the following equation:

$C_{\mathrm{sw}}=\frac{d_{\mathrm{p}}}{d_{\mathrm{p}_{\mathrm{o}}}}$

where $d_{\mathrm{p}}$ is the average diameter of the particles and $d_{\mathrm{po}}$ is the average diameter of the parent fuel.

Based on the morphological results, the swelling factor of the studied coal is 0.7 . As a result, it is increasingly difficult to measure experimentally. For this work, ranges from 0.5 to 1 are considered uncertain.

The char oxidation rates are predicted by the following equation (Hurt et al. 1998):

$\frac{\mathrm{d} m_{\mathrm{p}}}{\mathrm{d} t}=A_{\mathrm{p}} k\left(P_{O_{2}, \infty}-\frac{\mathrm{d} m_{\mathrm{p}}}{\mathrm{d} t} \frac{1}{S_{\mathrm{p}} D}\right)^{n}$

where $m_{\mathrm{p}}$ is the mass of the particle; $A_{\mathrm{p}}$ is the external surface area of the particle, which is calculated according to the particle size $d_{\mathrm{p}} ; P_{\mathrm{O}_{2}, \infty}$ is the oxygen partial pressure; $n$ is the apparent reaction order; $k$ is the apparent kinetic rate; and $D$ is the external diffusion rate coefficient calculated as follows (Morgan and Roberts 1987):

$k=A_{\mathrm{a}} \exp \left(-\frac{E_{\mathrm{a}}}{R T}\right)$

$D=2.57 \times 10^{-7} \frac{\left[\left(T_{\mathrm{p}}+T_{\infty}\right) / 2\right]^{0.75}}{d_{\mathrm{p}}}$.

The evaluated diameter is modelled according to the following equation:

$\frac{d_{\mathrm{p}}}{d_{\mathrm{p}, 0}}=(1-X)^{\alpha}$

where $A_{\mathrm{a}}$ is the apparent pre-exponential factor; $E_{\mathrm{a}}$ is the apparent activation energy; $d_{\mathrm{p}}$ is the particle diameter (the subscript 0 indicates the initial value); $X$ is the degree of burnout.

According to Hurt work (1998), the density and particle size are evolved during the reaction gasification process. So the particle density should be model basin the particle mass and diameter.

The burning mode $(\alpha)$ is ranged between 0 and $\frac{1}{3}$. If it decreases to the minimum 0 , this situation corresponds to regime (I) which has a decreasing density with constant particle size. On the contrary, if the burning mode reaches the maximum $\frac{1}{3}$, this situation refers to regime (III) which has a constant density with decreasing particle size. Additionally, in regime (II), the burning mode depends on both the combustion conditions and the particle size. In this model, the burning mode is adjusted to $\frac{1}{4}$ due to its influence on the burnout prediction at the late combustion stages (Karlström et al. 2011).

\subsection{Governing equations}

In the current model, the transport equations are based on the equations of conservative mass, energy, momentum, species reaction and fluid state. In addition, the system uses a time-averaged or spatially filtered form because the actual flow is always turbulent. The diffusion of fluid in the bed is diffusion and turbulence (Di Blasi 2004). Table 4 shows the governing equations of solid and gas phases.

Table 5 shows the main interactions between phases, Convection heat transfer and momentum (the drag in gases and solids) stress in granular solids shows the inelasticity of solid particles by moving random particles and molecules in heat gases. The intensity of velocity fluctuation determines the stress, viscosity and pressure of particle phase. Compared with fluid-solid momentum transfer, the solid-solid momentum transfer is less. Because of the velocity difference, it is assumed that the resistance between phases is safe.

Moreover, Table 6 clarifies the radiative and convective heat transfer depending on the Rosseland model (1936). In addition, Table 7 illustrates the mass and heat transport correlations.

Coal gasification is a multiphase flow problem. It is a multiphase problem between gas and coal particles, and it is also a reactive flow. In this study, Euler-Euler method is used. The gasification model of gasified fixed bed is designed to help understand the physicochemical and mechanical phenomena in the fixed bed during gasification.

Calculation of homogeneous and heterogeneous solidgas reactions are introduced in the present model. In the present work, the finite-rate model is utilized for the heterogeneous reactions. Both the finite-rate and eddydissipation models are considered for the homogeneous reaction, and the smaller of the two is used as the reaction rate. The finite-rate model calculates the reaction rates in view of the kinetics, while the eddy-dissipation model calculates based on the turbulent mixing rate of the flow.

After the solid phase calculation is completed, the gas phase is consumed or produced through the matter and updated as a result of energy changes caused by heterogeneous reactions. The iteration continues until the gas 
Table 6 Heterogeneous and homogeneous reactions in the fixed bed gasifier

\begin{tabular}{|c|c|c|}
\hline No. & Chemical reactions & Kinetic equations \\
\hline $\begin{array}{l}\text { Heterogeneous } \\
\text { reactions }\end{array}$ & $\begin{array}{l}\mathrm{C}+\frac{1}{\emptyset} \mathrm{O}_{2} \rightarrow\left(2-\frac{2}{\emptyset}\right) \mathrm{CO}+\left(\frac{2}{\emptyset}-1\right) \mathrm{CO}_{2} \\
\text { The parameter } \emptyset \text { is function on the fuel } \\
\text { temperature } \\
\emptyset=\frac{2+2512 \exp \left(\frac{-6420}{T_{\mathrm{s}}}\right)}{2\left(1+2512 \exp \left(\frac{-642}{T_{\mathrm{s}}}\right)\right)} \\
\mathrm{C}+\mathrm{CO}_{2} \rightarrow 2 \mathrm{CO} \text { (Boudouard reaction) } \\
\mathrm{C}+\mathrm{H}_{2} \mathrm{O} \rightarrow \mathrm{CO}+\mathrm{H}_{2} \text { (water }+ \text { gas) } \\
\mathrm{C}+\frac{1}{2} \mathrm{O}_{2} \rightarrow \mathrm{CO}(\text { partial combustion) } \\
\mathrm{C}+2 \mathrm{H}_{2} \rightarrow \mathrm{CH}_{4} \text { (Methanation reaction) }\end{array}$ & $\begin{array}{l}r=\pi d^{2} k_{\mathrm{c}} C_{\mathrm{O}_{2}}(\mathrm{~mol} / \mathrm{s}) \\
k_{\mathrm{c}}=\frac{R_{\mathrm{u}} T / M_{\mathrm{c}}}{\left(1 / k_{\mathrm{cr}}\right)+\left(1 / k_{\mathrm{cd}}\right)}(\mathrm{kg} / \mathrm{s}) \\
k_{\mathrm{cr}}=8710 \cdot \exp \left(-\frac{1.4947 \times 10^{8}}{R_{\mathrm{u}} T}\right)\left(\mathrm{kg} / \mathrm{m}^{2} \mathrm{~s} \mathrm{kpa}\right) \\
k_{\mathrm{cd}}=\frac{12 \cdot S h \cdot \emptyset \cdot D_{\mathrm{g}}}{d_{\mathrm{p}} \cdot R_{\mathrm{g}} \cdot T}\left(\mathrm{~kg} / \mathrm{m}^{2} \mathrm{~s} \mathrm{kpa}\right) \\
S h=\frac{k_{\mathrm{g}} d_{\mathrm{p}}}{D_{\mathrm{g}}}=2 \phi+0.69\left(\frac{R e_{\mathrm{p}}}{\phi}\right)^{1 / 2} S c^{1 / 3} \\
r=4364 \exp \left(-\frac{29,844}{T_{\mathrm{p}}}\right) C_{\mathrm{CO}_{2}}\left(\mathrm{~mol} / \mathrm{m}^{3} \mathrm{~s}\right) \\
k_{1}=4.93 \times 10^{3} \exp \left(-\frac{18,522}{T_{\mathrm{p}}}\right) \\
k_{2}=1.11 \times 10 \exp \left(-\frac{3548}{T_{\mathrm{p}}}\right) \\
k_{3}=1.53 \times 10^{-9} \exp \left(-\frac{25,161}{T_{\mathrm{p}}}\right) \\
k_{4}=0.052 \exp \left(-\frac{6.1 \times 10^{7}}{R T_{\mathrm{p}}}\right) \\
k_{5}=6 \times 10^{-7} \exp \left(-\frac{7.53 \times 10^{7}}{R T_{\mathrm{p}}}\right)\end{array}$ \\
\hline $\begin{array}{l}\text { Homogeneous } \\
\text { reactions }\end{array}$ & $\begin{array}{l}\mathrm{CH}_{4}+\mathrm{H}_{2} \mathrm{O} \rightarrow \mathrm{CO}+3 \mathrm{H}_{2} \text { (stream reforming) } \\
\mathrm{CH}_{4}+\mathrm{O}_{2} \rightarrow \mathrm{CO}+2 \mathrm{H}_{2} \\
\mathrm{CO}+\frac{1}{2} \mathrm{O}_{2} \rightarrow \mathrm{CO}_{2} \\
\mathrm{CO}+\mathrm{H}_{2} \mathrm{O} \rightarrow \mathrm{CO}_{2}+\mathrm{H}_{2} \text { (water-gas-shift) } \\
\mathrm{H}_{2}+\frac{1}{2} \mathrm{O}_{2} \rightarrow \mathrm{H}_{2} \mathrm{O}\end{array}$ & 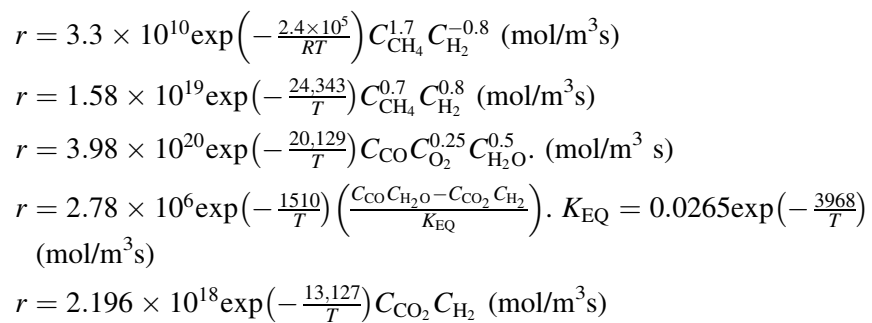 \\
\hline
\end{tabular}

phase and solid phase converge, the use of computational fluid dynamics (CFD) simulation is an economical and efficient tool for the study of coal gasification. The detailed computational model is as follows (Tables 8, 9, 10).

\subsection{Aspen plus model}

A thermodynamic equilibrium model of pressurized fixed bed gasifier is established by using Aspen plus. The equilibrium model can predict the system's thermodynamic constraints accurately and quickly, and the simulation results can be used as the basis for process design evaluation and improvement. In the future, the effects of oxygen and steam quantity and preheating temperature on the gas production and effective gas composition of the synthetic gas are investigated to provide the reference for the selection of the operating parameters of the device.

Aspen Plus is a general chemical process simulation software. On the basis of material balance, heat balance, phase equilibrium and chemical balance, Aspen Plus provides a large amount of physical data, strict thermodynamic estimation model library, and rich process unit model library, which can be used to simulate various industrial processes. In providing reliable thermodynamic data, operation parameters and accurate device models, Aspen Plus can be applied to the simulation of actual production units. Based on the Aspen Plus chemical process simulation software, the Gibbs free energy minimization method was used to establish and simulate the gasification coke grading oxygen supply pressurized fixed bed gasifier model, and the Aspen Plus physical property database and the unit model were used to calculate the model. The carbon conversion data and the estimated heat loss in actual industrial operation are introduced to correct the simulation results (Aspen Technology 2000).

According to the gasification process and mechanism of fixed bed gasifier, the following assumptions are made (Zhu et al. 2011):

(1) The combustion and gasification processes are considered as steady-state processes in the simulation.

(2) It is assumed that the pressure inside the reactor bed is constant. 
Table 7 Governing equations (Kader 1981; Gupta et al. 2003)

\begin{tabular}{|c|c|c|}
\hline No. & Parameter & Governing equation \\
\hline 1 & Gas phase continuity equation & $\frac{\partial\left(\phi \rho_{\mathrm{g}}\right)}{\partial t}+\nabla\left(\phi \rho_{\mathrm{g}} u_{\mathrm{g}}\right)=S_{\mathrm{sg}}$ \\
\hline 2 & Solid phase continuity equation & $\frac{\partial\left((1-\phi) \rho_{\mathrm{s}}\right)}{\partial t}+\nabla\left((1-\phi) \rho_{\mathrm{s}} u_{\mathrm{s}}\right)=-S_{\mathrm{sg}}$ \\
\hline 3 & Gas phase momentum equation & $\frac{\partial\left(\phi \rho_{\mathrm{g}} u_{\mathrm{g}}\right)}{\partial t}+\nabla\left(\phi \rho_{\mathrm{g}} u_{\mathrm{g}} u_{\mathrm{g}}\right)=-\phi \nabla P_{\mathrm{g}}+\phi \rho_{\mathrm{g}} g-\beta\left(u_{\mathrm{g}}-u_{\mathrm{s}}\right)+\nabla \phi \tau_{\mathrm{g}}$ \\
\hline 4 & $\begin{array}{l}\text { The governing equations for } \mathrm{k} \\
\text { and } \varepsilon\end{array}$ & $\begin{array}{l}\frac{\partial}{\partial t}\left(\phi \rho_{\mathrm{g}} k\right)+\nabla\left(\phi \rho_{\mathrm{g}} u_{\mathrm{g}} k\right)=+\nabla\left(\phi \frac{\mu_{t}}{\sigma_{k}} \nabla k\right)+\phi G_{k}-\phi \rho_{\mathrm{g}} \epsilon \\
\frac{\partial}{\partial t}\left(\phi \rho_{\mathrm{g}} \varepsilon\right)+\nabla\left(\phi \rho_{\mathrm{g}} u_{\mathrm{g}} \varepsilon\right)+\nabla\left(\phi \frac{\mu_{t}}{\sigma_{\varepsilon}} \nabla \varepsilon\right)+\phi\left(C_{\varepsilon 1} G_{k}-C_{\varepsilon 2} \rho_{\mathrm{g}} \epsilon\right)\end{array}$ \\
\hline 5 & $\begin{array}{l}\text { Solid phase momentum } \\
\text { equation }\end{array}$ & $\frac{\partial\left((1-\phi) \rho_{\mathrm{s}} u_{\mathrm{s}}\right)}{\partial t}+\nabla\left((1-\phi) \rho_{\mathrm{s}} u_{\mathrm{s}} u_{\mathrm{s}}\right)=-(1-\phi) \nabla P_{\mathrm{s}}+(1-\phi) \rho_{\mathrm{s}} g-\beta\left(u_{\mathrm{g}}-u_{\mathrm{s}}\right)+\nabla(1-\phi) \tau_{\mathrm{s}}$ \\
\hline 6 & Gas phase energy equation & $\frac{\partial\left((1-\phi) \rho_{\mathrm{s}} c_{\mathrm{ps}} T_{\mathrm{s}}\right)}{\partial t}+\nabla\left(\phi \rho_{\mathrm{g}} u_{\mathrm{g}} c_{\mathrm{pg}} T_{\mathrm{g}}\right)=\nabla\left(\lambda_{\mathrm{g}} \cdot \nabla T_{\mathrm{g}}\right)+A_{\mathrm{s}} h_{\mathrm{s}}\left(T_{\mathrm{g}}-T_{\mathrm{s}}\right)+S_{T_{\mathrm{g}}}$ \\
\hline 7 & Solid phase energy equation & $\frac{\partial\left((1-\phi) \rho_{\mathrm{s}} c_{\mathrm{ps}} T_{\mathrm{s}}\right)}{\partial t}+\nabla\left((1-\phi) \rho_{\mathrm{s}} u_{\mathrm{s}} c_{\mathrm{ps}} T_{\mathrm{s}}\right)=\nabla\left(k_{\mathrm{eff}} \cdot \nabla T_{\mathrm{s}}\right)+\left(\nabla q_{\mathrm{r}}\right)-A_{\mathrm{s}} h_{\mathrm{s}}\left(T_{\mathrm{g}}-T_{\mathrm{s}}\right)+S_{T_{\mathrm{s}}}$ \\
\hline 8 & Gas phase species equation & $\frac{\partial\left(\phi \rho_{\mathrm{g}} Y_{\mathrm{ig}}\right)}{\partial t}+\nabla\left(\phi \rho_{\mathrm{g}} u_{\mathrm{g}} Y_{\mathrm{ig}}\right)=\nabla\left(D_{\mathrm{ig}} \nabla\left(\phi \rho_{\mathrm{g}} Y_{\mathrm{ig}}\right)\right)+S_{Y_{\mathrm{g}}}$ \\
\hline 9 & Solid phase species equation & $\frac{\partial\left((1-\phi) \rho_{\mathrm{s}} Y_{\mathrm{is}}\right)}{\partial t}+\nabla\left((1-\phi) \rho_{\mathrm{s}} u_{\mathrm{s}} Y_{\text {is }}\right)=S_{Y_{\mathrm{s}}}$ \\
\hline \multicolumn{3}{|c|}{$\begin{array}{l}\text { Here } Y_{\text {ig }} \text { is the species mass fraction, } D_{\text {ig }} \text { is the fluid dispersion coefficient as expressed in Ismail and Abd El-Salam (2017) and } Y_{\text {is }} \text { is the particle } \\
\text { mass fraction composition (moisture, volatile and fixed carbon). The source term of the species equation for both gas and solid is calculated } \\
\text { individually for each species and particle composition }\end{array}$} \\
\hline \multicolumn{3}{|c|}{ Source terms } \\
\hline \multicolumn{2}{|c|}{$\begin{array}{l}\text { Continuity equation } \\
\text { Energy equation }\end{array}$} & $S_{\mathrm{sg}}=R_{\mathrm{evp}}+R_{\mathrm{v}}+R_{\mathrm{c}}$ \\
\hline Ener & gy equation & $\begin{array}{l}S_{\mathrm{Tg}}=-R_{\mathrm{evp}} \times h_{\mathrm{f}, \mathrm{CO}} \text { gas-phase } \\
S_{\mathrm{Ts}}=-R_{\mathrm{evp}} \times \frac{M_{\mathrm{CO}}}{M_{\mathrm{CO}}} \times\left[h_{\mathrm{f}, \mathrm{CO} 2}-h_{\mathrm{f}, \mathrm{CO}}\right] \times\left[\frac{Y_{\mathrm{CO}}}{2}-1\right] \text { solid-phase } \\
S_{\mathrm{sg}}=R_{\mathrm{evp}}+R_{\mathrm{v}}+R_{\mathrm{c}} S_{\mathrm{sg}} \text { is the conversion rate from solid to gases due to evaporation, devolatilization } \\
\quad \text { and char burning }\end{array}$ \\
\hline
\end{tabular}

(3) The model includes the processes of fixed-bed gasification, including coal drying, coal pyrolysis, carbon gasification and combustion, and drying and pyrolysis occur rapidly at the top of the gasifier.

(4) A one-dimensional assumption is made to assume that the gas has no concentration and temperature gradient in the radial direction.

\subsubsection{Physical method}

The PR-BM model was applied to the physical properties, and the related components were divided into two categories: conventional components and unconventional components. The conventional components (for example, $\mathrm{CO}, \mathrm{CO}_{2}, \mathrm{H}_{2}, \mathrm{H}_{2} \mathrm{O}$, etc.) use PR-BM model equation to calculate their thermodynamic properties. The unconventional components are coal and ash. We think it is not directly involved in chemical reaction and phase equilibrium but only calculate its enthalpy and density. The enthalpy of coal is calculated by HCOALGEN model, and the density of coal is calculated by DCHARIGT model.

\subsubsection{Setting of unit modules}

The fixed-bed gasifier can be divided into five zones: dry layer, distillation layer, gasification layer, combustion layer and ash bed. The simulation flow chart of the fixed-bed gasifier is shown in Fig. 3. The drying layer was simulated by RSTOIC and FLASH2 modules.

The Decomp module is a yield reactor in Aspen Plus, which can simulate reactions with unknown or unimportant stoichiometric and kinetic data. But it is necessary to know the yield distribution of the reaction product. Its primary function is to dry the coal and decompose it into single element molecule and transfer the pyrolysis heat to the next combustion unit, where Eq. (11) is the equation of enthalpy equilibrium of the modified reaction. Where $Q$ is pyrolysis heat, the enthalpy of formation of coal is calculated by Eq. (12), and carbon conversion is set by the model. 
Table 8 Hydrodynamic mode 1

\begin{tabular}{ll}
\hline The inter-phase drag coefficient when $\phi \leq 0.8$ & $\beta=150 \frac{(1-\phi)^{2} \mu_{\mathrm{T}}}{\phi d_{\mathrm{p}}^{2}}+1.75 \frac{\rho_{\mathrm{g}}(1-\phi)\left|U_{\mathrm{g}}-U_{\mathrm{s}}\right|}{d_{\mathrm{p}}}$ \\
Gas phase stress tensor & $\tau_{g}=\mu_{g}\left[\nabla u_{g}+\nabla u_{\mathrm{g}}^{T}\right]-\frac{2}{3} \mu_{T}\left(\nabla u_{g}\right)$
\end{tabular}

$$
\tau_{g}=\mu_{g}\left[\nabla u_{g}+\nabla u_{g}^{T}\right]-\frac{2}{3} \mu_{T}\left(\nabla u_{g}\right)
$$

The effective viscosity, $\mu_{\mathrm{T}}$, which is the summation of laminar viscosity, $\mu_{\mathrm{g}}$, and turbulent viscosity, $\mu_{\mathrm{t}}$ is expressed as follows:

Effective viscosity

$$
\begin{aligned}
& \mu_{\mathrm{T}}=\mu_{\mathrm{g}}+\mu_{\mathrm{t}} \\
& \mu_{\mathrm{t}}=\rho_{\mathrm{g}} C_{\mu} \frac{k^{2}}{\varepsilon} C_{\mu} \text { is the constant, set as } 0.09 \\
& G_{\mathrm{k}}=\mu_{\mathrm{t}} \nabla u_{\mathrm{g}} \cdot\left[\nabla u_{\mathrm{g}}+\nabla u_{\mathrm{g}}^{T}\right]-\frac{2}{3} \nabla u_{\mathrm{g}}\left(\mu_{\mathrm{t}} \nabla u_{\mathrm{g}}+\rho_{\mathrm{g}} k\right)
\end{aligned}
$$$$
\text { Turbulent viscosity }
$$

Generation of turbulence kinetic energy

The following values have been used for the model constants Monteiro et al. (2018) $C_{\varepsilon 1}=1.44$ and $C_{\varepsilon 2}=1.92$, the turbulent Prandtl numbers for $\mathrm{k}$ and $\varepsilon$. are $\sigma_{k}=1$ and $\sigma_{\varepsilon}=1.3$, respectively.

Stress tensor of the solid phase

Bulk viscosity

Solid shear viscosity

Solid pressure

Radial distribution function of solid phase

The granular temperature

The fluctuating velocity of the particles

Void fraction in the bed

$$
\begin{aligned}
& \tau_{\mathrm{s}}=\left(\mu_{\mathrm{b}}-\frac{2}{3} \mu_{\mathrm{s}}\right) \nabla u_{\mathrm{s}}+\mu_{\mathrm{s}}\left(\nabla u_{\mathrm{s}}+u_{\mathrm{s}}^{T}\right) \\
& \mu_{\mathrm{b}}=\frac{4}{3}(1-\phi) \rho_{\mathrm{s}} d_{\mathrm{p}} g_{\mathrm{o}} \\
& \mu_{\mathrm{s}}=\frac{4}{5}(1-\phi) \rho_{\mathrm{s}} d_{\mathrm{p}} g_{\mathrm{o}}(1+e) \sqrt{\frac{\Theta_{\mathrm{s}}}{\pi}}+\frac{10 \rho_{\mathrm{s}} d_{\mathrm{p}} \sqrt{\pi \Theta_{\mathrm{s}}}}{96(1+e) g_{\mathrm{o}}}\left[1+\frac{4}{5} g_{\mathrm{o}}(1-\phi)(1+e)\right]^{2} \\
& P_{\mathrm{s}}=(1-\phi) \rho_{\mathrm{s}} \Theta_{\mathrm{s}}+2(1+e)(1-\phi)^{2} g_{\mathrm{o}} \rho_{\mathrm{s}} \Theta \\
& g_{\mathrm{o}}=\frac{3}{5}\left[1-\left(\frac{(1-\phi)}{(1-\phi)_{\max }}\right)^{\frac{1}{3}}\right]^{-1} \\
& \frac{3}{2} \Theta_{\mathrm{s}}=\frac{1}{2} u_{\mathrm{s}}^{\prime} u_{\mathrm{s}}^{\prime} \\
& u_{\mathrm{s}}^{\prime}=\zeta(2 k / 3)^{0.5} \text { Where } \zeta \text { is a random number that obeys the Gauss distribution, } 0 \leq \zeta \leq 1 \\
& \phi=\phi^{\circ} \frac{\mathrm{V}_{\mathrm{o}}}{\mathrm{V}} \frac{\mathrm{V}_{\mathrm{o}}}{\mathrm{V}}=1-a_{1}\left(R_{\mathrm{dry}}^{\circ}-R_{\mathrm{dry}}\right)-a_{2}\left(R_{\mathrm{v}}^{\circ}-R_{\mathrm{v}}\right)-a_{3}\left(R_{\mathrm{c}}^{\circ}-R_{\mathrm{c}}\right)
\end{aligned}
$$

$a_{1}, a_{2}, a_{3}$ are coefficients equal to 1 or 0 according to the appearance of moisture, devolatilization, and char burnout, respectively

Table 9 Interphase heat transfer

\begin{tabular}{lll}
\hline No. & Parameter & Equation \\
\hline Heat and mass transfer model & \\
1 & Radiative flux density & $\nabla q_{\mathrm{r}}=-\frac{16 \sigma T^{2}}{K}(\nabla T)^{2}+\frac{16 \sigma T^{3}}{3 K}\left(\nabla^{2} T\right)$ \\
2 & Thermal dispersion coefficient & $\lambda_{\mathrm{g}}=k_{\mathrm{eff}, 0}+0.5 \times d_{\mathrm{p}} \times U_{\mathrm{g}} \times \rho_{\mathrm{g}} \times C_{\mathrm{pg}}$ \\
3 & Thermal conductivity for no fluid flow & $k_{\mathrm{eff}, 0}=\phi\left(k_{\mathrm{f}}+h_{\mathrm{rv}} \Delta l\right)+\frac{(1-\phi) \Delta l}{1 /\left(\frac{k_{\mathrm{f}}}{l_{\mathrm{v}}} h_{\mathrm{rs}}\right)+l_{\mathrm{s}} / k_{\mathrm{s}}}$ \\
4 & Effective radiation heat transfer coefficient & $h_{\mathrm{rv}}=0.1952\left(1+\frac{\phi(1-\epsilon)}{2(1-\phi) \epsilon}\right)^{-1}\left(\frac{T_{\mathrm{s}}}{100}\right)^{n}$. \\
5 & Radiation heat transfer coefficient for radiation at contact surface & $h_{\mathrm{rs}}=0.1952 \times d_{\mathrm{p}}\left(\frac{\epsilon}{2-\epsilon}\right)\left(\frac{T_{\mathrm{s}}}{100}\right)^{n}$ \\
6 & $\mathrm{n}$ is an empirical parameter related to the fuel packing conditions & $n=1.93+0.67 \mathrm{exp}\left(-\frac{\left(m_{\mathrm{g}}-0.39\right)}{0.054}\right)$ \\
7 & Characteristic distance between two particles & $\Delta l=0.96795 d_{\mathrm{p}}(1-\phi)^{-\frac{1}{3}}$ \\
8 & Air thermal conductivity & $k_{\mathrm{air}}\left(T_{\mathrm{g}}\right)=5.66 \times 10^{-5} T_{\mathrm{g}}+1.1 \times 10^{-2}$. \\
9 & Equivalent thickness a layer of solid & $l_{\mathrm{s}}=\frac{2 d_{\mathrm{p}}}{3}$ \\
\hline
\end{tabular}

The Burn cell is a reactor based on the principle of Gibbs free energy minimization. Both chemical equilibrium and phase equilibrium can be calculated simultaneously. The unit is used to simulate the gasification layer and combustion layer in the fixed bed gasifier. The components contained in $\mathrm{C}, \mathrm{H}, \mathrm{O}, \mathrm{N}, \mathrm{S}$ are as follows: $\mathrm{H}_{2} \mathrm{O}, \mathrm{N}_{2}, \mathrm{O}_{2}, \mathrm{~S}$, $\mathrm{H}_{2}, \mathrm{Cl}_{2}, \mathrm{HCl}, \mathrm{C}$ (solid), $\mathrm{CO}, \mathrm{CO}_{2}, \mathrm{H}_{2} \mathrm{~S}, \mathrm{CH}_{4}, \mathrm{H}_{3} \mathrm{~N}, \mathrm{CHN}$, COS, etc. 
Table 10 Heat and mass transport correlations used in the present model (Green and Perry 1999; Kremer 2011)

\begin{tabular}{lll}
\hline No. & Parameter & Equation \\
\hline 1 & Heat transfer rate from solid and gas to wall is expressed as: & $Q_{\mathrm{sw}}=\frac{4 h_{\mathrm{w}}^{\mathrm{s}}}{d_{\mathrm{ia}}}\left(T_{\mathrm{s}}-T_{\mathrm{w}}\right)$ \\
& & $Q_{\mathrm{gw}}=\frac{4 h_{\mathrm{w}}^{\mathrm{g}}}{d_{\mathrm{ia}}}\left(T_{\mathrm{g}}-T_{\mathrm{w}}\right)$ \\
2 & Solid-to-wall heat transfer coefficient & $h_{\mathrm{w}}^{\mathrm{s}}=\frac{k_{\mathrm{rs}}}{k_{\mathrm{rg}}+k_{\mathrm{rs}}} h_{\mathrm{w}}$ \\
3 & Gas-to-wall heat transfer coefficient & $h_{\mathrm{w}}^{\mathrm{g}}=\frac{k_{\mathrm{rg}}}{k_{\mathrm{rs}}+k_{\mathrm{rg}}} h_{\mathrm{w}}$ \\
4 & Bed-to-wall heat transfer coefficient & $h_{\mathrm{w}}=\frac{2.44 k_{\mathrm{eff}, 0}}{d_{\mathrm{ia}}^{4 / 3}}+\frac{0.033 k_{\mathrm{g}} P r R e}{d_{\mathrm{p}}}$ \\
\hline
\end{tabular}

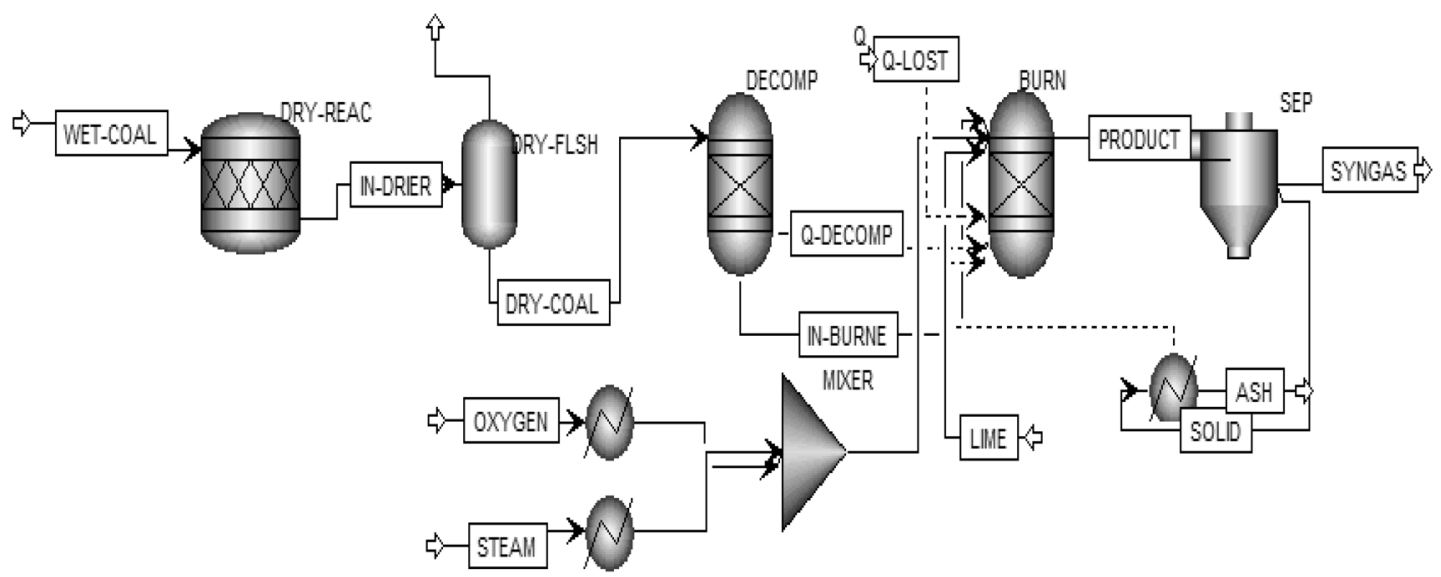

Fig. 3 Schematic diagram of fixed-bed gasification model

When the equilibrium criterion is reached, the Gibbs free energy of the reactor is minimized. The Separate unit is an ideal separator from the SSplit module. Its function is to separate crude syngas from cinder.

According to the results of the pilot test, the byproducts of gasification are tar, light oil, BTX, phenols and concentrated ammonia water. Due to ASPEN don't have tar, light oil BTX, Phenols, Concentrated ammonia component.

$\mathrm{C}_{15} \mathrm{H}_{30-1}, \mathrm{C}_{10} \mathrm{H}_{18-1}, \mathrm{C}_{6} \mathrm{H}_{6}, \mathrm{C}_{6} \mathrm{H}_{6} \mathrm{O}, \mathrm{NH}_{4} \mathrm{OH}$ were selected to represent the five by-products mentioned above (Pickett 2000), and its yield was determined to modify the simulation.

(1) Operating conditions and model checking

The industrial and elemental analysis of coal quality used in this simulation is shown in Table 1, and the calorific value of coal is $26.67 \mathrm{MJ} / \mathrm{kg}$. The gasification operation conditions used in this simulation are shown in Tables 1 and 2.

(2) The simulated data are compared with the experimental results.

From Table 11 the simulation results are close with the experimental data. The present work uses the mathematical model of Aspen Plus to establish a fixed bed gasification reactor, to simulate the coal gasification process, the simulation data and the experimental data is in good agreement, as shown from the relative errors between the experimental and simulated values. In future, the model can be used to investigate the effect of oxygen and steam and preheating temperature on the composition of gas and gas production the influence of effective gas, provide a reference for the operation of the device parameters.

\subsection{Numerical methods and boundary conditions}

The transport equations described earlier form a set of nonlinear parabolic partial differential equations that can be solved numerically, using the SIMPLE algorithm.

The transport equations are generalized into a standard form:

$\frac{\partial \rho \Phi}{\partial t}+\frac{\partial \rho u \Phi}{\partial x}+\frac{\partial \rho V \Phi}{\partial y}=\frac{\partial}{\partial x}\left(\Gamma \frac{\partial \Phi}{\partial x}\right)+\frac{\partial}{\partial y}\left(\Gamma \frac{\partial \Phi}{\partial y}\right)+S_{\Phi}$

Here $\rho$ is the density, $u$ and $V$ are velocities, $\Phi$ is the parameter to be solved, $\Gamma$ is the transport coefficient, and 
Table 11 Comparison of simulation results with experimental results (mole fraction)

\begin{tabular}{llll}
\hline Species & $\begin{array}{l}\text { Experimental } \\
\text { value }\end{array}$ & $\begin{array}{l}\text { Aspen plus model } \\
\text { value }\end{array}$ & $\begin{array}{l}\text { Error } \\
(\%)\end{array}$ \\
\hline $\mathrm{H}_{2}$ & 25.93 & 25.72 & 0.8 \\
$\mathrm{CO}$ & 62.77 & 62.36 & 0.67 \\
$\mathrm{CH}_{4}$ & 4.05 & 4.16 & 2.7 \\
$\mathrm{CO}_{2}$ & 5.94 & 6.34 & 6.7 \\
$\mathrm{H}_{2} \mathrm{~S}, \mathrm{COS}$ and & 0.69 & 0.75 & 8.7 \\
$\quad \mathrm{CS}$ & & & 66.6 \\
$\mathrm{NH}_{3}, \mathrm{HCl}$ and & 0.03 & 0.01 & \\
$\quad \mathrm{HCN}$ & & & 22 \\
$\mathrm{~N}_{2}$ and $\mathrm{Ar}$ & 0.36 & 0.44 & 23 \\
$\mathrm{C}_{n} \mathrm{H}_{m}$ & 0.3 & 0.23 & \\
\hline
\end{tabular}

$S_{\Phi}$ is the source term. The bulk density of our pellets is about $400 \mathrm{~kg} / \mathrm{m}^{3}$.

The governing equations (presented above) are discretized into a system of algebraic equations, using the Upwind Difference Scheme on a staggered grid system (Patankar 1980; Tao 2001). The total number of grid cells is 200,000 with uniform time step is $10^{-4}$. The mesh adapts to the height of the gasifier at each time step.

Several methods of discretization of differential equations with partial derivatives are currently used. Given our case, the method used is that of the finite volume. The finite volume method is characterized by its advantage in satisfying mass, momentum, and energy conservation in all finite volumes and throughout the computational domain.

It facilitates the linearization of nonlinear terms in conservation equations, such as the source term. The method involves sharing the computational domain in multiple volumes or through each volume surrounding a node. Using different approximation schemes, we can integrate the terms of the modeling differential equations on each control volume. The algebraic equations produced to express the conservation of quantities for the control volume and throughout the computational domain. The bed domain is discretized into many small cells, and Eq. (13) is discretized for every cell equation by the finite volume method (FVM).

The shrinkage model is considered in the present model, where the particle size changes during the gasification stage, starting with drying, to pyrolysis, and finishing with char burnout. This assumption prevents the occurrence of channeling in the bed and allows the observed temperature to be fully addressed in the model.

The kinetic rate reaction is a key in the modeling of coal gasification in a fixed bed gasifier. Kinetic reaction rates are divided into two main reactions; oxidation reaction (combustion zone) and reduction reaction (gasification zone). These two main reactions are classified as homogeneous and heterogeneous reactions. The advanced kinetic model used in the present model shows the different reactions along the reactor height, which in turn allows visual observation of what happens within the gasifier; this leads to better fitting predicted values for produced gases and heating value.

A comprehensive basic investigation begins with twodimensional geometry. Based on 2D results, in simulations, different fluid properties are calculated for each species and gas mixture, taking buoyancy into account. And the wall is considered impervious and adiabatic. The flow is stable and the wall surfaces are a no-slip condition (zero velocity).

The temperature distribution of all four meshes in twodimensional geometry is very small, as shown in Fig. 4. Therefore, in order to save computing time with accurate results, the medium grid of 200,000 cells is selected for further parameter study, as well as is also selected for the near wall $\mathrm{y}+$ of a two-dimensional grid.

\section{Model validation}

The durability, efficiency, performance, and utility of the presented mathematical model can be evaluated by comparing the results from the presented model with the present experimental data.

The proposed mathematical models can be evaluated by comparing the results of the models provided with the experimental data. Figure 5 and Table 12 illustrate the comparison between the existing experimental results and numerical models for the syngas compositions. The results obtained by the model are in good agreement with the experimental results.

The carbon balance in gasification process is calculated, and it is found that the experimental and numerical results are very similar. The carbon conversion is calculated by the ratio of carbon in the product gas to the carbon in the coal, which is obtained from the final analysis as the weight benchmark. It can be expressed numerically as (Konttinen et al. 2012):

$\mathrm{CCE}=\frac{\text { Total, carbon, outlet, syngas }}{\text { Carbon, in, feedstock }} \times 100 \%$

Cold-gas efficiency (CGE) is the energy input over the potential energy output based on the HHV of both the solid fuel and the product gas (Zainal et al. 2001; Chen et al. 2013):

$\mathrm{CGE}=\frac{\dot{m}_{\mathrm{g}} \Sigma H H V_{\mathrm{g}}}{\dot{m}_{\text {in,fuel }} \Sigma H H V_{\text {fuel }}}$ 




Fig. 4 Temperature distributions for the different grid sizes of the 2-D geometry

where $H H V_{\text {fuel }}$ and $H H V_{\mathrm{g}}\left(\mathrm{H}_{2}, \mathrm{CO}\right.$ and $\left.\mathrm{CH}_{4}\right)$ are the lower heating value of the coal and of the product gas, respectively. $\dot{m}_{\text {in,fuel }}$ and $\dot{m}_{\mathrm{g}}$ are the coal feeding rate and gas production rate, respectively. Therefore, CGE can be analyzed based on the numerator of Eq. (15) since the denominator can be considered constant.

Based on the above comparisons, the proposed numerical model is valid and provides an effective simulation for the combustion/gasification of coal in the main technology of gasification in fixed-bed gasifier.

\section{Numerical results}

Figure 6 shows the concentration of gaseous products vary significantly with both axial and radial positions. The concentration of $\mathrm{H}_{2}$ and $\mathrm{CO}$ is very less at the bottom of the gasifier. This is because in coal gasification, the major contributions of these gases are from the volatile matter and their homogeneous reactions. The species $\mathrm{CO}_{2}$ and $\mathrm{CH}_{4}$ show a larger mole concentration at the bottom of the gasifier. Concentration of $\mathrm{H}_{2}$ and $\mathrm{CO}$ increases along the height of the gasifier. On the other hand, the concentration of $\mathrm{CO}_{2}$ and $\mathrm{CH}_{4}$ is more above the coal injection port and then decrease along the height. This is because that $\mathrm{O}_{2}$ reacts exhaustively in the bottom portion of the gasifier, so there is no $\mathrm{O}_{2}$ present in the freeboard region. That means the $\mathrm{O}_{2}$ depletion takes place concurrently with pyrolysis which confirms that the gasification is taking place in the rest of the gasifier region.
Figure 7 shows the distribution of gas temperature and gas composition in the gasifier. The oxidized coal particles react immediately upon entering the gasifier. The char is based on the exothermic reaction $\left(\mathrm{C}+0.5 \mathrm{O}_{2} \rightarrow \mathrm{CO}\right)$, where combustion of char produces carbon monoxide and raises the temperature. The carbon monoxide produced by the above reaction then reacts with the remaining air, through the reaction of $\mathrm{CO}+0.5 \mathrm{O}_{2} \rightarrow \mathrm{CO}_{2}$ releases carbon dioxide, heat and further raises the temperature. The heat released from homogeneous and heterogeneous reactions provides the energy required for all other endothermic reactions under limited oxidation conditions.

The temperature distribution of each nozzle in the gasifier is simulated as the flame shape. The outer space temperature of the oxidant jet is the highest, which is $1900-2000{ }^{\circ} \mathrm{C}$. Coal particles react with gaseous fuel gas under combustion conditions. Syngas and slag remain at $1600{ }^{\circ} \mathrm{C}$, which is higher than the melting point of ash. Ash and flue gas will be discharged smoothly together.

To further understand the physical process simulation of heterogeneous reactions such as combustion reaction, the reaction rate of water gas shift reaction and thermal cracking reaction. Figure 8 illustrates in the fixed bed combustion rate relates to the heterogeneous and homogeneous reaction model. It can be seen that once in the coal bed, the rapid release of volatile, and the reaction speed is 10-1000 times faster than other. The homogeneous reaction rate showed that the volatile products in the upper part of the bed combustion significantly. From the study of some model of the middle zone completely volatile combustion assumptions may not be accurate, especially for the 


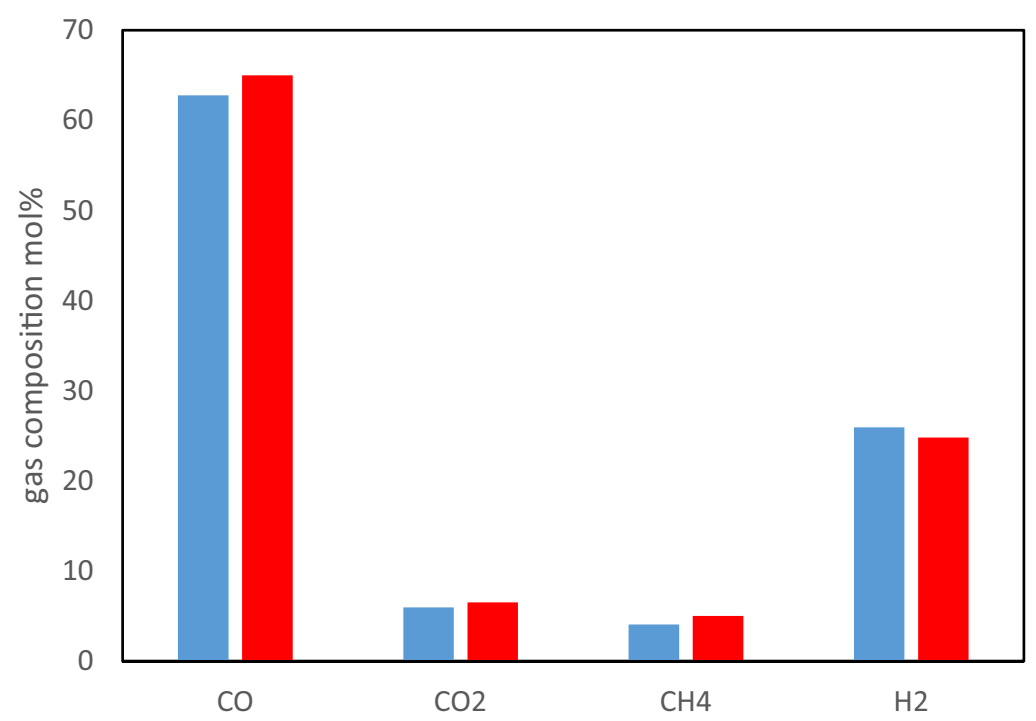

Experimental work

- Present Model

Fig. 5 Experimental and predicted syngas compositions

Table 12 Comparison between experimental and current simulation results

\begin{tabular}{llll}
\hline Item & Syngas temperature $\left({ }^{\circ} \mathrm{C}\right)$ & CCE $(\%)$ & CGE $(\%)$ \\
\hline Experimental work & 442 & 99 & 89 \\
Present model & 450 & 98 & 87 \\
\hline
\end{tabular}

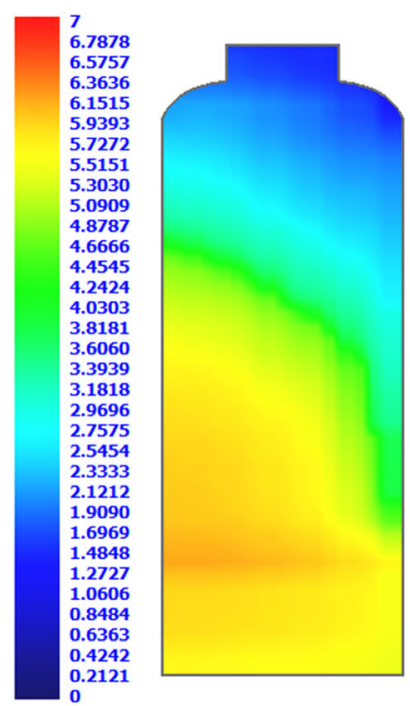

$\mathrm{CO} 2$

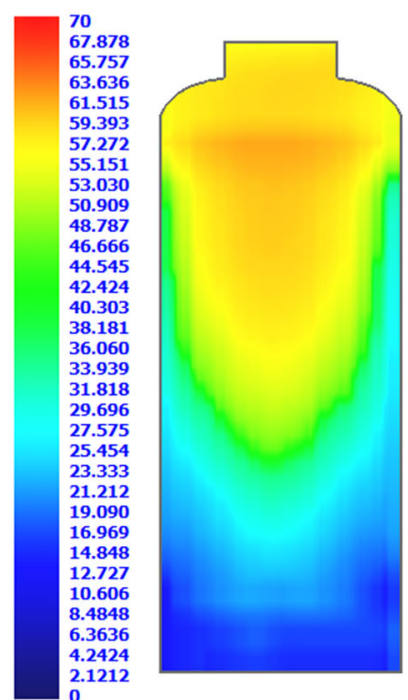

co

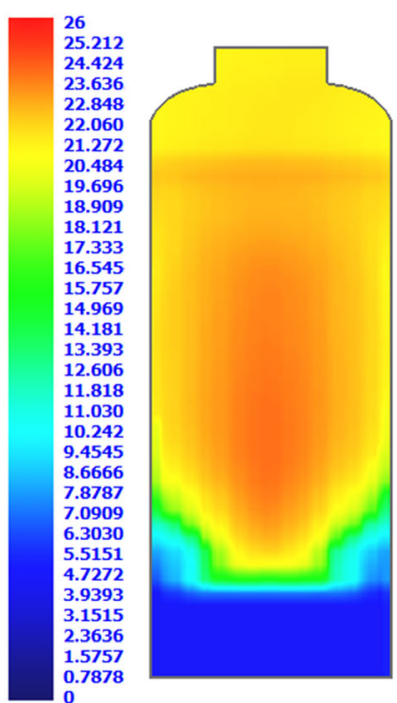

$\mathrm{H} 2$

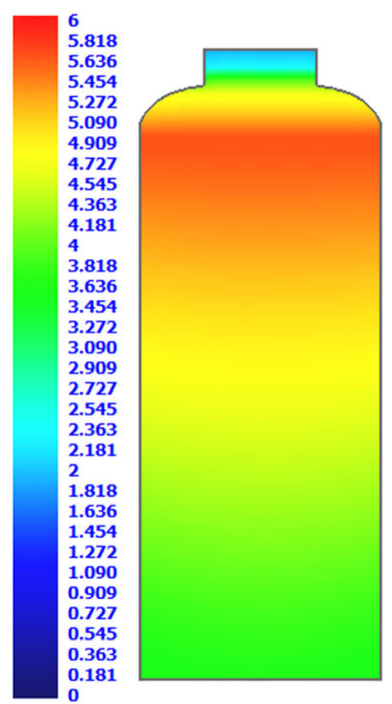

$\mathrm{CH} 4$

Fig. 6 Gas species contour distribution in the gasifier (mol\%) 
1800

1746.21

1692.42

1638.63

1584.84

1531.06

1477.27

1423.48

1369.69

1315.90

1262.12

1208.33

1154.54

1100.75

1046.97

993.181

939.394

885.606

831.818

778.030

724.242

670.454

616.666

562.878

509.090

455.303

401.515

347.727

293.939

240.151

186.363

132.575

78.7878

25
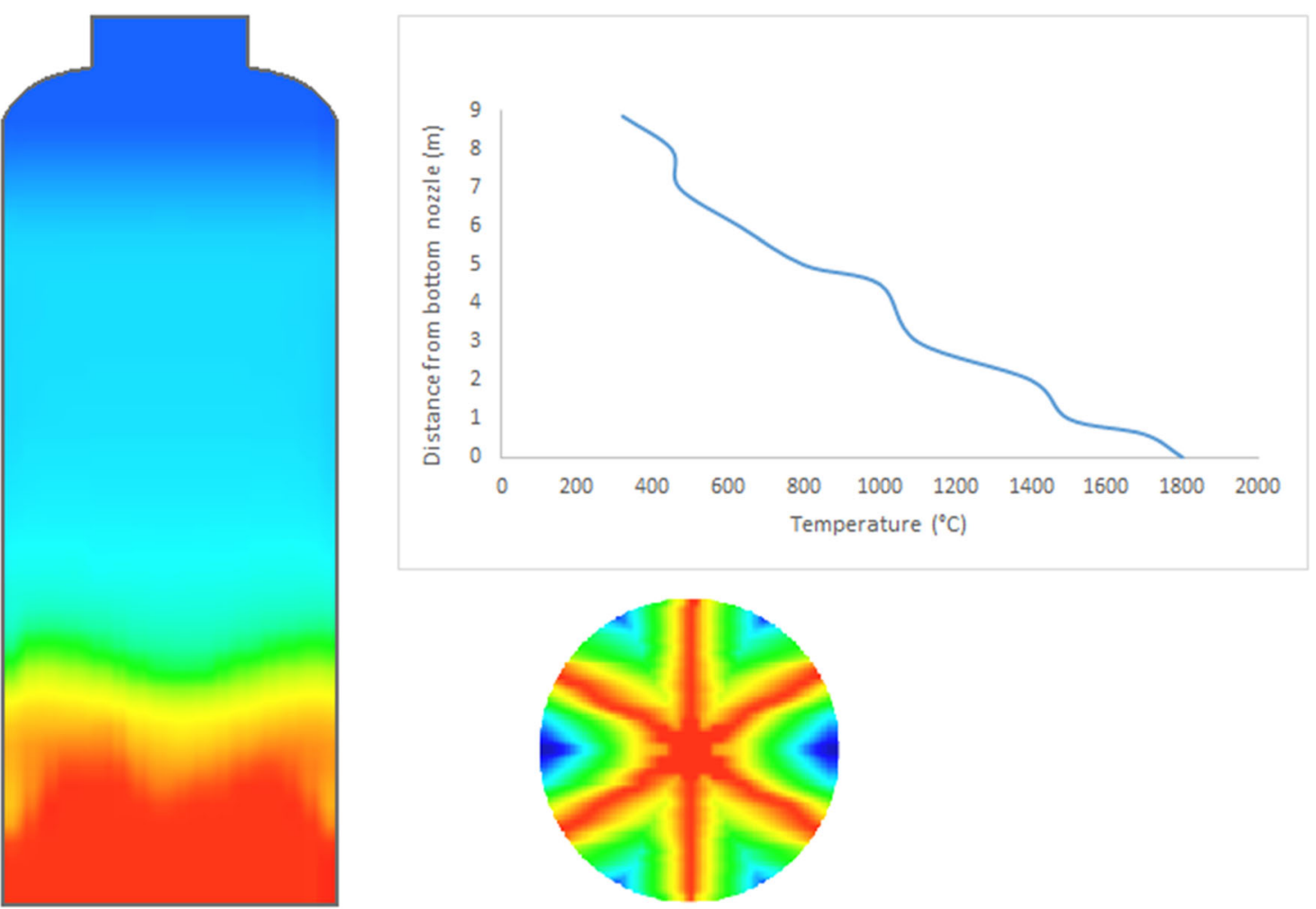

Fig. 7 Temperature contour distribution in the gasifier

high content of volatile bituminous coal. It can be seen from the figure, as shown in Figs. 5 and 6, high temperature at the bottom of the region, mainly due to the release of volatile combustion heat.

The combustion reaction of heterogeneous coal mainly occurred in the lower region and transition region. The comprehensive chemical kinetic reaction rate and oxygen diffusion rate of $k_{\mathrm{cd}}$ are to describe the coal burning rate. Figure 8 shows the $k_{\mathrm{cr}}$ is very high, indicating that the combustion rate of coal in the simulated conditions by kinetic reaction rate control for coal in the air in the combustion reaction, because the rate of low carbon gasification is negligible.

Figure 9 demonstrates the gasifier height (distance from bottom nozzle) effect on the syngas mean mole fractions.
The average hydrogen molar fraction is almost stable after the reactor height is $3 \mathrm{~m}$. In addition, the average mole fraction of carbon monoxide increases along the reactor height. The growth rate of carbon monoxide is very small. By showing all the reaction rates along the reactor height, the reactor height effect can be more clearly understood.

Figures 10 and 11 show the heterogeneous and homogeneous reaction rates changes in the reactor height, respectively. As shown in these Figs., the reactions of R6, R7, and R8 are stopped due to a lack of oxygen. The main reason is that the average mole fraction of oxygen after the second meter of the reactor is less than 0.09, as shown in Fig. 9. The rate of water gas shift reaction is shown in Fig. 7. Because of the reactor temperature is below $900 \mathrm{~K}$, it is almost zero after the reactor height is $6 \mathrm{~m}$. 


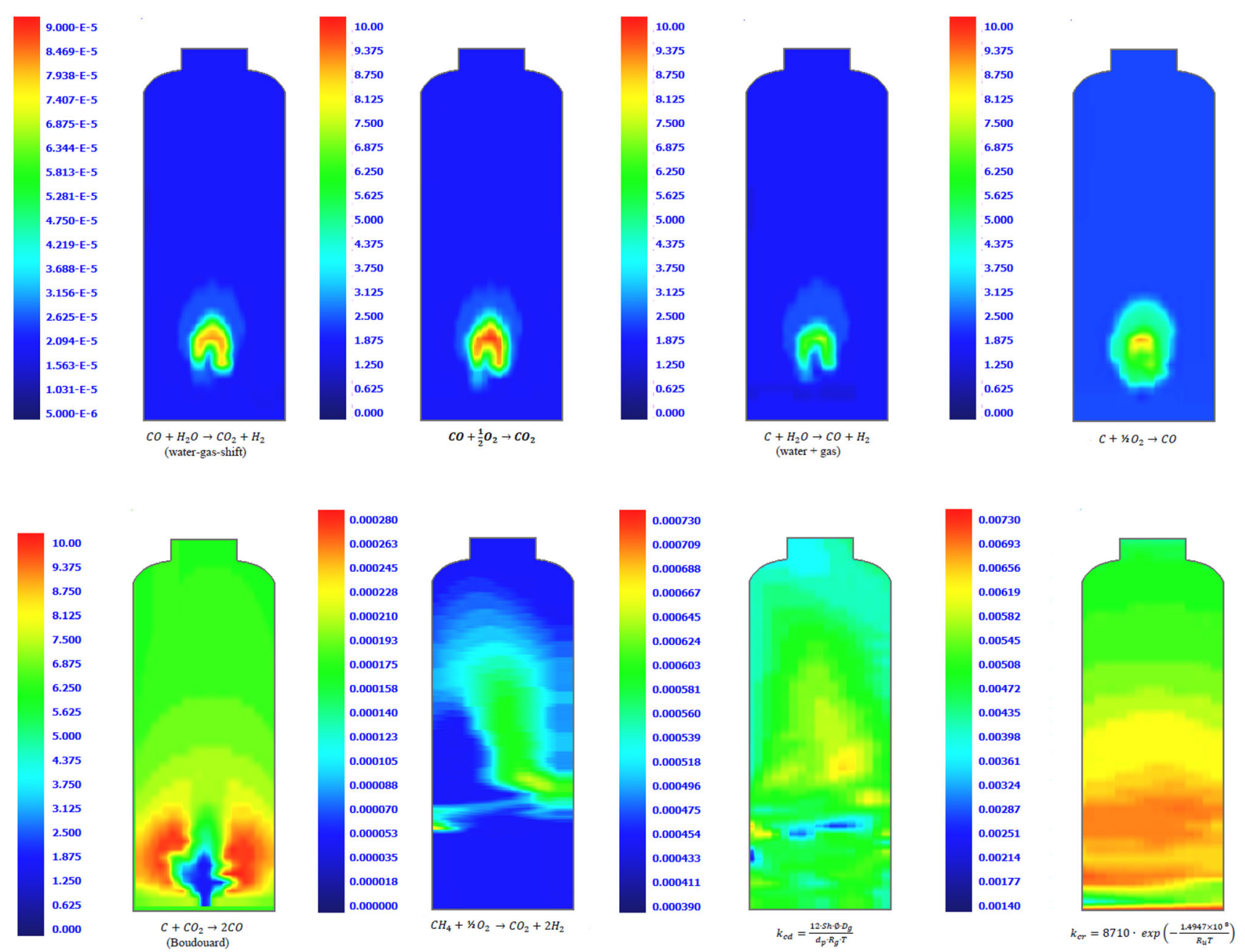

Fig. 8 Reaction rate contour in the gasifier

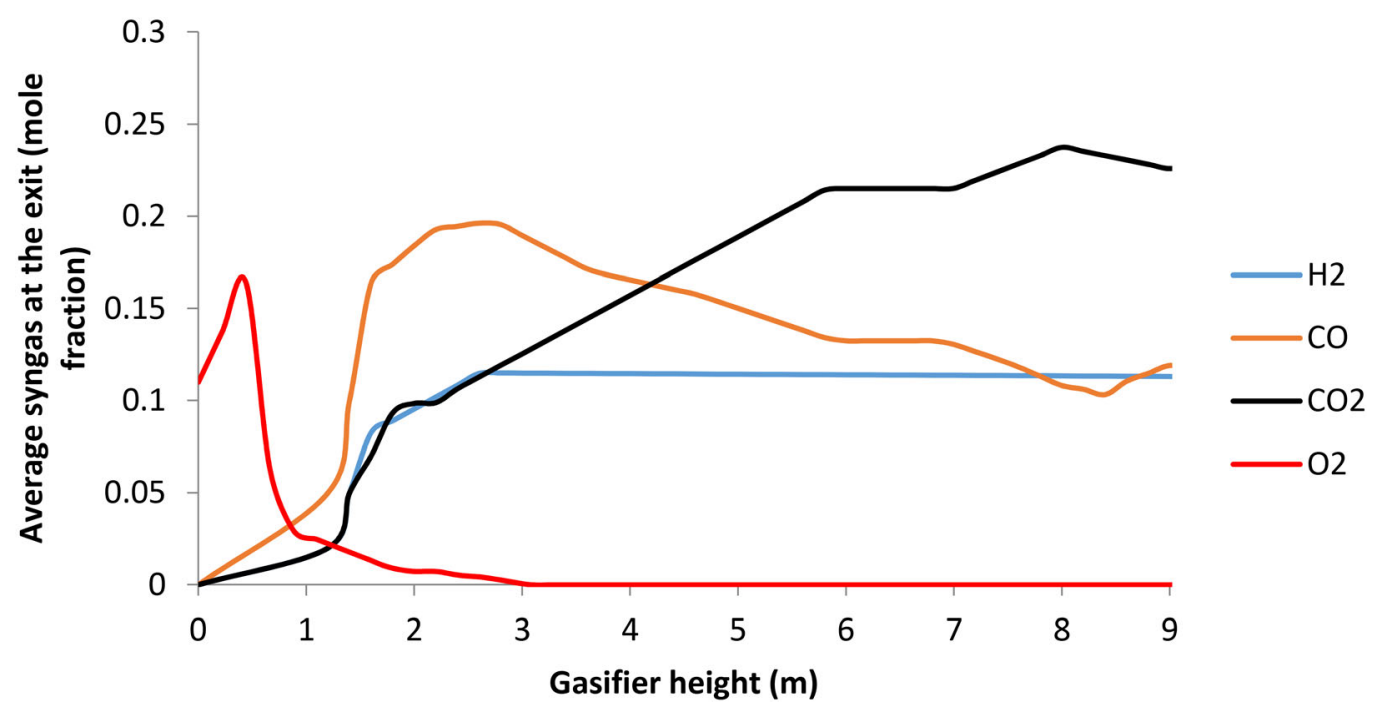

Fig. 9 Average syngas (mole fractions) along gasifier height at the exit 

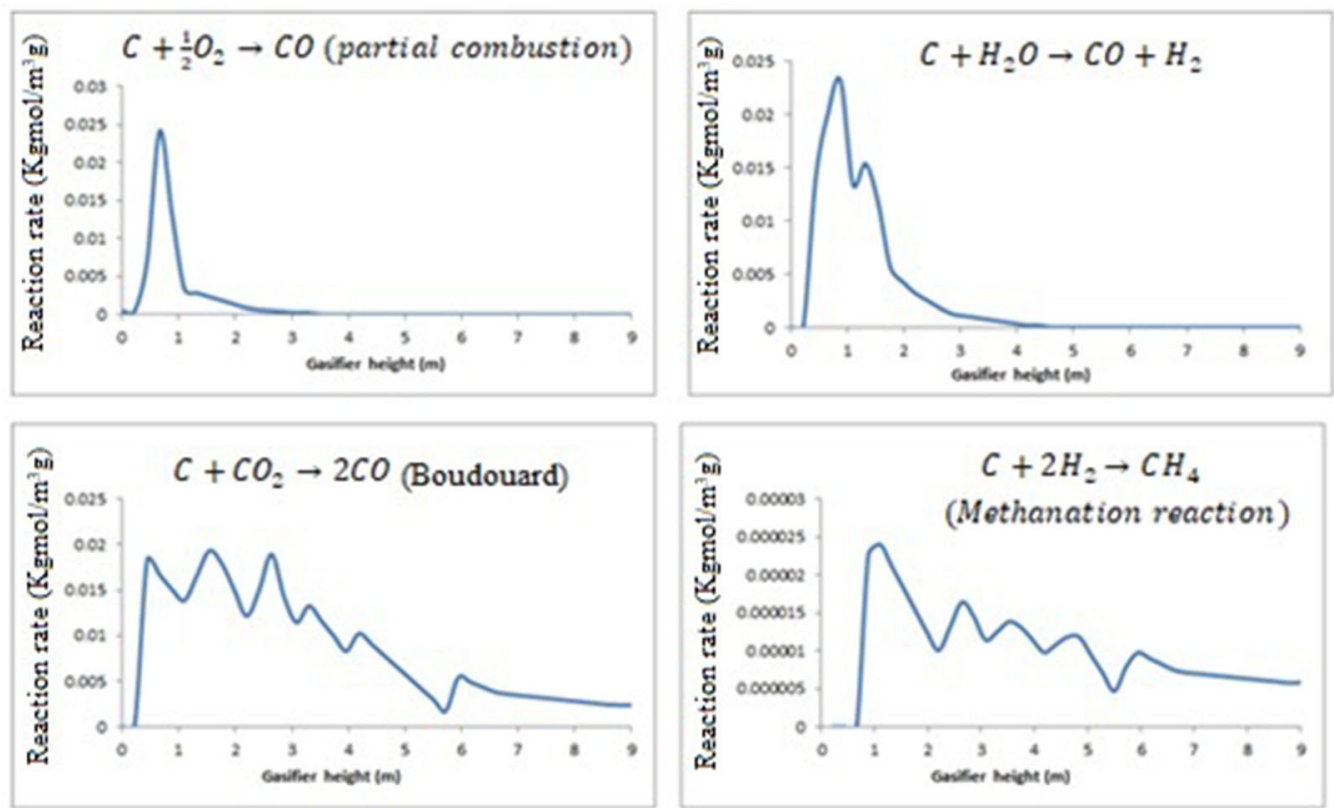

Fig. 10 Heterogeneous reaction rates along gasifier height
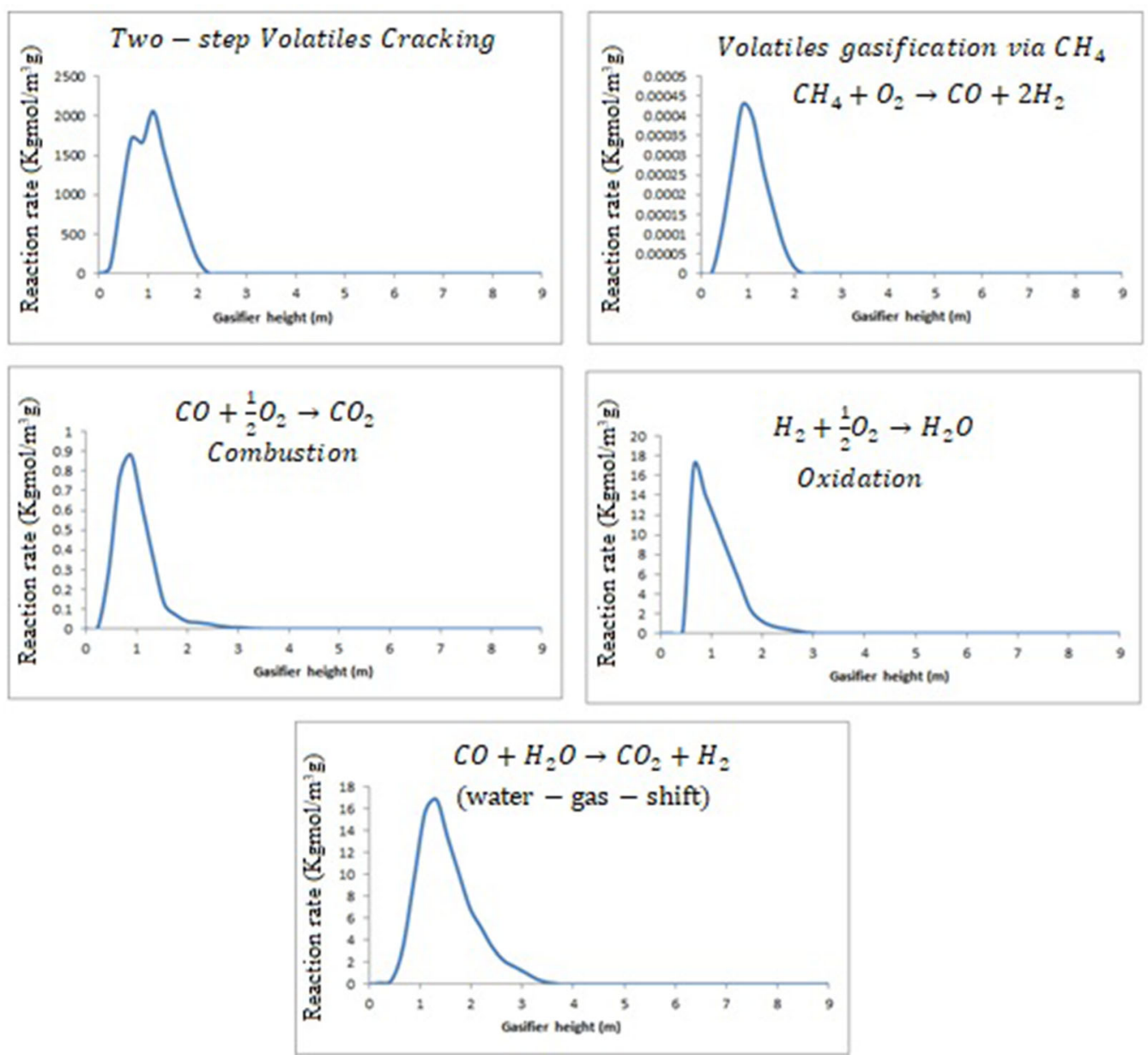

Fig. 11 Homogenous reaction rates along gasifier height 


\section{Arrhenius kinetic rate constant}

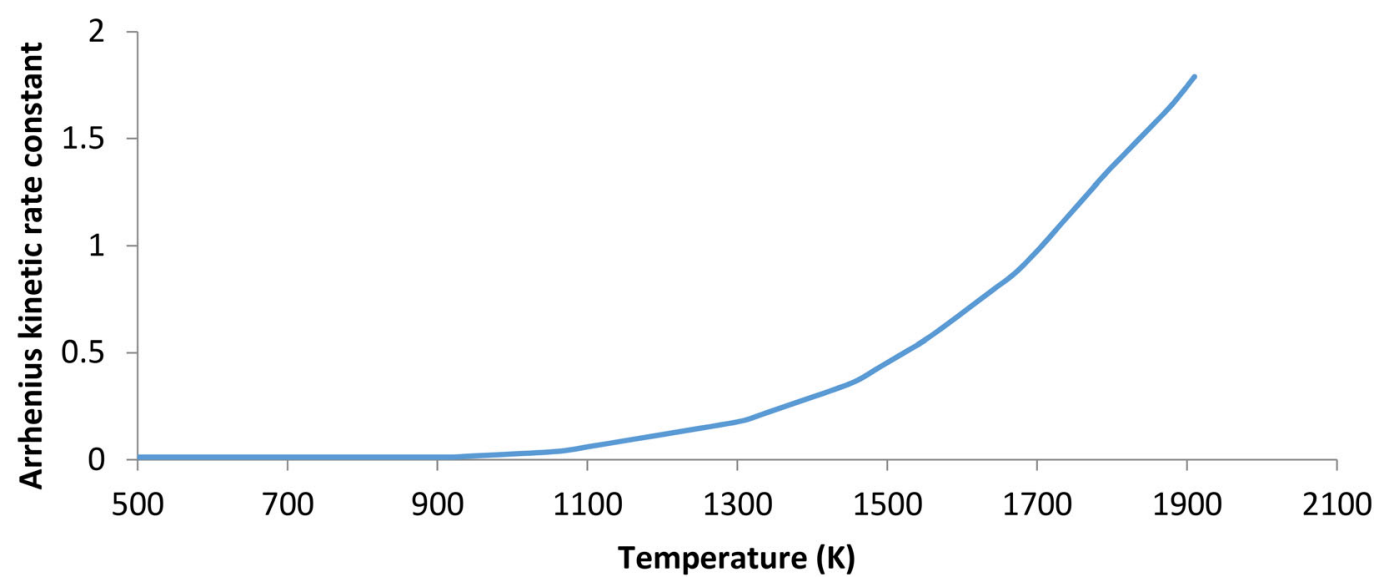

Fig. 12 Arrhenius kinetic rate constant changing for water gas shift reaction versus temperature

Arrhenius kinetic rate constant, $k$, is shown in Fig. 12 for water gas shift reaction. As shown in this figure, the rate is very small below $1000 \mathrm{~K}$. Because of the lack of oxygen and water vapor in the medium, combustion and gasification reactions disappear after the third meters in the height of the reactor.

Boudouard reaction is the key reaction along the reactor height especially above the second meter because it increases the average mole fraction of carbon monoxide very effectively. Figure 9 shows that the average mole fraction of carbon monoxide increases as the average mole fraction of carbon dioxide decreases. The main reason is that, as shown in Fig. 10, Boudouard reaction is still active, and the average molar fraction of carbon dioxide peaks with temperature and then decreases due to the main reaction with carbon monoxide (Boudouard reaction).

\section{Conclusions}

This paper presents a promising tool for simulating the coal gasification process in a fixed bed gasifier. Two kinds of simulation tools are used in this method.

One method is Computational Fluid Dynamics (CFD). Based on the Eulerian-Eulerian model, chemical reaction kinetics model and particle shrinkage model were added to our home-made code. A developed and validated two dimensional CFD model for coal gasification has been used to predict and assess the viability of the syngas generation from coal gasification employing the updraft fixed bed gasifier.

The other method is Aspen Plus. Based on the principle of Gibbs free energy minimization, the method uses different cell modules to simulate five different regions in a fixed bed reactor.

A comparison between the data from the pilot experiment with those of the two models are conducted, and the results showed that the three had good consistency. It shows that CFD and Aspen Plus model can be used to simulate the fixed bed gasifier. In the absence of experimental data, the two can verify the reliability of the simulation data.

Besides, in the future, these two models could be used to simulate different operation conditions on the gasification efficiency and syngas quality in the fixed bed gasifier, so as to get the best operation conditions.

Acknowledgements The research was supported by the National Key Research and Development Project (2016YFB060040202).

Open Access This article is licensed under a Creative Commons Attribution 4.0 International License, which permits use, sharing, adaptation, distribution and reproduction in any medium or format, as long as you give appropriate credit to the original author(s) and the source, provide a link to the Creative Commons licence, and indicate if changes were made. The images or other third party material in this article are included in the article's Creative Commons licence, unless indicated otherwise in a credit line to the material. If material is not included in the article's Creative Commons licence and your intended use is not permitted by statutory regulation or exceeds the permitted use, you will need to obtain permission directly from the copyright holder. To view a copy of this licence, visit http://creativecommons. org/licenses/by/4.0/.

\section{Appendix 1: Correlations used in the present model.}

See Tables 13, 14 and 15. 
Table 13 Expressions of integral heat capacity at constant pressure of gaseous species and the char depending on the temperature between $T_{0}=298 \mathrm{~K}$ and $T$ (Lu et al. 2018)

\begin{tabular}{ll}
\hline Species & $\int_{T_{0}}^{T} C p_{\mathrm{k}} \mathrm{d} T(\mathrm{~J} / \mathrm{mol}), T_{0}=298 \mathrm{~K}$ \\
\hline $\mathrm{CH}_{4}$ & $\left(5.34\left(T-T_{0}\right)+\frac{0,0115}{2} \times\left(T-T_{0}\right)^{2}\right) \times 4.1855$ \\
$\mathrm{O}_{2}$ & $\left(8.27\left(T-T_{0}\right)+\frac{0.000258}{2} \times\left(T-T_{0}\right)^{2}+\frac{187700}{T}\right) \times 4.185$ \\
$\mathrm{CO}$ & $\left(6.6\left(T-T_{0}\right)+\frac{0.0012}{2} \times\left(T-T_{0}\right)^{2}\right) \times 4.1855$ \\
$\mathrm{CO}_{2}$ & $\left(10.34\left(T-T_{0}\right)+\frac{0.00274}{2} \times\left(T-T_{0}\right)^{2}+\frac{195500}{\left(T-T_{0}\right)} \times 4.1855\right.$ \\
$\mathrm{H}_{2} \mathrm{O}_{(\mathrm{V})}$ & $\left(8.22\left(T-T_{0}\right)+\frac{0.00015}{2} \times\left(T-T_{0}\right)^{2}+\frac{0.00000134}{3} \cdot\left(T-T_{0}\right)^{3}\right) \times 4.1855$ \\
$\mathrm{H}_{2}$ & $\left(6.62\left(T-T_{0}\right)+\frac{0.00018}{2} \times\left(T-T_{0}\right)^{2}\right) \times 4.1855$ \\
$\mathrm{~N}_{2}$ & $\left(6.5\left(T-T_{0}\right)+\frac{0.001}{2} \times\left(T-T_{0}\right)^{2}\right) \times 4.1855$ \\
$\mathrm{Char}$ & $\left(1.39\left(T-T_{0}\right)+\frac{0.00036}{2} \times\left(T-T_{0}\right)^{2}\right) \times M_{C}$ \\
\hline
\end{tabular}

Table 14 Expression of the thermal conductivity of gaseous species and carbon as a function of temperature (Monteiro et al. 2018; Lu et al. 2018)

\begin{tabular}{llll}
\hline Species & Thermal conductivity $\left(\mathrm{mW} \mathrm{m}^{-1} \mathrm{~K}^{-1}\right)$ & Validity \\
\hline $\mathrm{N}_{2}$ & $\left(-0.3721+0.10977 \cdot T-9.42549 \cdot 10^{-5} \cdot T^{2}+8.05548 \cdot 10^{-8} \cdot T^{3}-3.35367 \cdot 10^{-11} \cdot T^{4}+5.15605 \cdot 10^{-15} \cdot T^{5}\right)$ & $65-2500 \mathrm{~K}$ \\
$\mathrm{O}_{2}$ & $\left(-1.7536+0.1224 \cdot T-1.322444 \cdot 10^{-4} \cdot T^{2}+1.7804 \cdot 10^{-7} \cdot T^{3}-1.200176 \cdot 10^{-10} \cdot T^{4}+2.9817302 \cdot 10^{-14} \cdot T^{5}\right)$ & $70-1500 \mathrm{~K}$ \\
$\mathrm{CO}_{2}$ & $\left(-0.341914+0.0314 \cdot T+1.170458 \cdot 10^{-4} \cdot T^{2}-1.282 \cdot 10^{-7} \cdot T^{3}+5.7923 \cdot 10^{-11} \cdot T^{4}-9.72044 \cdot 10^{-15} \cdot T^{5}\right)$ & $190-2000 \mathrm{~K}$ \\
$\mathrm{H}_{2}$ & $\left(-4.0803+0.9858 \cdot T-1.330466 \cdot 10^{-3} \cdot T^{2}+1.1217 \cdot 10^{-6} \cdot T^{3}-3,25582 \cdot 10^{-10} \cdot T^{4}\right)$ & $16-1500 \mathrm{~K}$ \\
$\mathrm{CO}$ & $\left(-0.42832+0.09941 \cdot T-5.96573 \cdot 10^{-5} \cdot T^{2}+3.81583 \cdot 10^{-8} \cdot T^{3}-1.43131 \cdot 10^{-11} \cdot T^{4}+2.56748 \cdot 10^{-15} \cdot T^{5}\right)$ & $80-2200 \mathrm{~K}$ \\
$\mathrm{H}_{2} \mathrm{O}$ & 148 & & $1500 \mathrm{~K}$ \\
$\mathrm{C}$ & 95.8 &
\end{tabular}

Table 15 Expression of the mass diffusivity of gaseous species as a function of temperature (Chapaman-Enskog formula) (Mermoud 2006)

\begin{tabular}{ll}
\hline Gas species & Massive diffusivity $D_{\mathrm{j} / \mathrm{N} 2}\left(\mathrm{~m}^{2} / \mathrm{s}\right)$ \\
\hline $\mathrm{N}_{2}$ & $1.39 \times 10^{-4} \times\left(\frac{1.013 \times 10^{5}}{p}\right) \times\left(\frac{T}{1173}\right)^{3 / 2}$ \\
$\mathrm{CO}_{2}$ & $1.13 \times 10^{-4} \times\left(\frac{1.013 \times 10^{5}}{p}\right) \times\left(\frac{T}{1173}\right)^{3 / 2}$ \\
$\mathrm{H}_{2} \mathrm{O}$ & $2.11 \times 10^{-4} \times\left(\frac{1.013 \times 10^{5}}{p}\right) \times\left(\frac{T}{1173}\right)^{3 / 2}$ \\
$\mathrm{CO}$ & $1.40 \times 10^{-4} \times\left(\frac{1.013 \cdot 10^{5}}{p}\right) \times\left(\frac{T}{1173}\right)^{3 / 2}$ \\
$\mathrm{H}_{2}$ & $5.11 \times 10^{-4} \times\left(\frac{1.013 \cdot 10^{5}}{p}\right) \times\left(\frac{T}{1173}\right)^{3 / 2}$ \\
$\mathrm{O}_{2}$ & $1.43 \times 10^{-4} \times\left(\frac{1.013 \cdot 10^{5}}{p}\right) \times\left(\frac{T}{1173}\right)^{3 / 2}$ \\
$\mathrm{CH}_{4}$ & $1.56 \times 10^{-4} \times\left(\frac{1.013 \cdot 10^{5}}{p}\right) \times\left(\frac{T}{1173}\right)^{3 / 2}$ \\
\hline
\end{tabular}

\section{References}

Ai Z, Wu L, Lin Y (2011) Numerical simulation of internal flow field of fixed bed gasifier. J Sanming Univ Res 28(5):65-69

Aspen Technology (2000) Aspen plus getting started solids. Aspen Technology, Bedford

Cau G, Cocco D, Serra F (2012) Energy and cost analysis of smallsize integrated coal gasification and syngas storage power plants. Energy Convers Manag 1(56): 121-129

Cetin E, Moghtaderi B, Gupta R, Wall TF (2004) Influence of pyrolysis conditions on the structure and gasification reactivity of biomass chars. Fuel 83(16):2139-2150

Chen S, Cao Z, Shi J et al (2012) Research on steady state simulation of fixed bed coal gasification based on ASPEN PLUS. Coal $\mathbf{J}$ 37(S1):167-172

Chen W-H, Chen C-J, Hung C-I, Shen C-H, Hsu H-W (2013) A comparison of gasification phenomena among raw biomass, torrefied biomass and coal in an entrained-flow reactor. Appl Energy 112:421-430

Di Blasi C (2004) Modeling wood gasification in a countercurrent fixed-bed reactor. AIChE J 50(9):2306-2319

Duan W, Yu Q, Wang K, Qin Q, Hou L, Yao X, Wu T (2015) ASPEN plus simulation of coal integrated gasification combined blast 
furnace slag waste heat recovery system. Energy Convers Manag 31(100):30-36

Golfier F, Mermoud F, Salvador S, Dirion J-L, Van de Steene L (2004) Modeling of char gasification at particle scale: how to select the best assumptions in the scope of fixed bed modelling

Green DW, Perry RH (1999) Perry's chemical engineers' handbook. McGraw-Hill, Cambridge

Gupta M, Yang J, Roy C (2003) Specific heat and thermal conductivity of softwood bark and softwood char particles. Fuel 82(8):919-927

Hurt R, Sun J-K, Lunden M (1998) A kinetic model of carbon burnout in pulverized coal combustion. Combust Flame 113(1-2):181-197

Institute of Clean Coal Technology (ECUST) (2005) Commercial plants of OMB coal-water slurry gasification. http://icct.ecust. edu.cn

Ismail TM, Abd El-Salam M (2017) Parametric studies on biomass gasification process on updraft gasifier high temperature air gasification. Appl Therm Eng 112:1460-1473

Ismail TM, El-Salam MA (2015) Numerical and experimental studies on updraft gasifier HTAG. Renew Energy 78(2):484-497

Ismail TM, Abd El-Salam M, Monteiro E, Rouboa A (2016) EulerianEulerian CFD model on fluidized bed gasifier using coffee husks as fuel. Appl Therm Eng 106:1391-1402

Ismail TM, El-Salam MA, Monteiro E, Rouboa A (2017) Fluid dynamics model on fluidized bed gasifier using agro-industrial biomass as fuel. Waste Manag 73:476-486

Kader BA (1981) Temperature and concentration profiles in fully turbulent boundary layers. Int $\mathrm{J}$ Heat Mass Transf 24(9):1541-1544

Karlström O, Brink A, Hupa M, Tognotti L (2011) Multivariable optimization of reaction order and kinetic parameters for high temperature oxidation of 10 bituminous coal chars. Combust Flame 158(10):2056-2063

Klose W, Wölki M (2005) On the intrinsic reaction rate of biomass char gasification with carbon dioxide and steam. Fuel 84(7):885-892

Kong X, Zhong W, Du W, Qian F (2014) Compartment modeling of coal gasification in an entrained flow gasifier: a study on the influence of operating conditions. Energy Convers Manag 1(82):202-211

Konttinen JT, Moilanen A, DeMartini N, Hupa M (2012) Carbon conversion predictor for fluidized bed gasification of biomass fuels-from TGA measurements to char gasification particle model. Biomass Convers Biorefinery 2(3):265-274

Kremer GM (2011) The methods of Chapman-Enskog and grad and applications

Liu L et al (2013) Simulation of gasification process of BGL coalfired slag gasifier. J Chem Eng 41(7):64-68

Lu D, Yoshikawa K, Ismail TM, El-Salam MA (2018) Assessment of the carbonized woody briquette gasification in an updraft fixed bed gasifier using the Euler-Euler model. Appl Energy 220:70-86
Lussier MG, Zhang Z, Miller DJ (1998) Characterizing rate inhibition in steam/hydrogen gasification via analysis of adsorbed hydrogen. Carbon 36(9):1361-1369

Manocha S, Chauhan VB, Manocha LM (2002) Porosity development on activation of char from dry and wet babbool wood. Carbon Lett 3(3):133-141

Masmoudi MA, Sahraoui M, Grioui N et al (2014) 2-D Modeling of thermo-kinetics coupled with heat and mass transfer in the reduction zone of a fixed bed downdraft biomass gasifier. Renew Energy 66(3):288-298

Mehrabian R, Shiehnejadhesar A, Scharler R et al (2014) Multiphysics modelling of packed bed biomass combustion. Fuel 122(4):164-178

Mermoud F (2006) Gazéification de charbon de bois à la vapeur d'eau: de la particule isolée au lit fixe continu. PhD diss., INPT

Monteiro E, Ismail TM, Ramos A, El-Salam MA, Brito PS, Rouboa A (2017) Assessment of the miscanthus gasification in a semiindustrial gasifier using a CFD model. Appl Therm Eng 1(123):448-457

Monteiro E, Ismail TM, Ramos A, El-Salam MA, Brito P, Rouboa A (2018) Experimental and modeling studies of Portuguese peach stone gasification on an autothermal bubbling fluidized bed pilot plant. Energy 1(142):862-877

Morgan ME, Roberts PA (1987) Coal combustion characterisation studies at the International Flame Research Foundation. Fuel Process Technol 15:173-187

Patankar S (1980) Numerical heat transfer and fluid flow. CRC Press, Boca Raton

Pickett MMR (2000) Modeling the performance and emissions of British Gas/Lurgi-based integrated gasification combined cycle system. North Carolina State University, Raleigh, pp 41-51

Prando D, Ail SS, Chiaramonti D, Baratieri M, Dasappa S (2016) Characterisation of the producer gas from an open top gasifier: assessment of different tar analysis approaches. Fuel 181:566-572

Rosseland S (1936) Theoretical astrophysics. The Clarendon press, Oxford, p 1936-1

Shabbar S, Janajreh I (2013) Thermodynamic equilibrium analysis of coal gasification using Gibbs energy minimization method. Energy Convers Manag 1(65):755-763

Tao WQ (2001) Numerical heat transfer. Xi' an Jiaotong University

Wu Y, Zhang Q, Yang W et al (2013) Two-dimensional computational fluid dynamics simulation of biomass gasification in a downdraft fixed-bed gasifier with highly preheated air and steam. Energy Fuels 27(6):3274-3282

Xu J, Liang Q, Dai Z, Liu H (2016) Comprehensive model with time limited wall reaction for entrained flow gasifier. Fuel 15(184):118-127

Zainal ZA, Ali R, Lean CH, Seetharamu KN (2001) Prediction of performance of a downdraft gasifier using equilibrium modeling for different biomass materials. Energy Convers Manag 42(12):1499-1515

Zhu Y, Wang D, Zhou J (2011) Simulation and optimization of fixed bed gasifier. J Chem Ind Eng 62(6):1606-1611 